Article

\title{
An "Animated Spatial Time Machine" in Co-Creation: Reconstructing History Using Gamification Integrated into 3D City Modelling, 4D Web and Transmedia Storytelling
}

\author{
Mario Matthys ${ }^{1,2,3, *}$, Laure De Cock ${ }^{1}\left(\mathbb{D}\right.$, John Vermaut $^{2}$, Nico Van de Weghe ${ }^{1}\left(\mathbb{D}\right.$ and Philippe De Maeyer ${ }^{1}(\mathbb{D}$ \\ 1 Department of Geography, Ghent University, Krijgslaan 281 (S8), 9000 Ghent, Belgium; \\ laudcock.decock@ugent.be (L.D.C.); nico.vandeweghe@ugent.be (N.V.d.W.); \\ philippe.demaeyer@ugent.be (P.D.M.) \\ 2 City of Ghent, 3D Team, Botermarkt 1,9000 Ghent, Belgium; john.vermaut@stad.gent \\ 3 Cosmopolis Centre for Urban Research, Department of Geography, Vrije Universiteit Brussel, Pleinlaan 2, \\ 1050 Brussels, Belgium \\ * Correspondence: mario.matthys@ugent.be
}

Citation: Matthys, M.; De Cock, L.; Vermaut, J.; Van de Weghe, N.; De Maeyer, P. An "Animated Spatial Time Machine" in Co-Creation: Reconstructing History Using Gamification Integrated into 3D City Modelling, 4D Web and Transmedia Storytelling. ISPRS Int. J. Geo-Inf. 2021, 10, 460. https://doi.org/ $10.3390 /$ ijgi10070460

Academic Editors: Wolfgang Kainz and Massimiliano Cannata

Received: 4 May 2021

Accepted: 2 July 2021

Published: 6 July 2021

Publisher's Note: MDPI stays neutral with regard to jurisdictional claims in published maps and institutional affiliations.

Copyright: (c) 2021 by the authors. Licensee MDPI, Basel, Switzerland. This article is an open access article distributed under the terms and conditions of the Creative Commons Attribution (CC BY) license (https:/ / creativecommons.org/licenses/by/ $4.0 /)$.

\begin{abstract}
More and more digital 3D city models might evolve into spatiotemporal instruments with time as the 4th dimension. For digitizing the current situation, 3D scanning and photography are suitable tools. The spatial future could be integrated using 3D drawings by public space designers and architects. The digital spatial reconstruction of lost historical environments is more complex, expensive and rarely done. Three-dimensional co-creative digital drawing with citizens' collaboration could be a solution. In 2016, the City of Ghent (Belgium) launched the "3D city game Ghent" project with time as one of the topics, focusing on the reconstruction of disappeared environments. Ghent inhabitants modelled in open-source 3D software and added animated 3D gamification and Transmedia Storytelling, resulting in a 4D web environment and VR/AR/XR applications. This study analyses this low-cost interdisciplinary $3 \mathrm{D}$ co-creative process and offers a framework to enable other cities and municipalities to realise a parallel virtual universe (an animated digital twin bringing the past to life). The result of this co-creation is the start of an "Animated Spatial Time Machine" (AniSTMa), a term that was, to the best of our knowledge, never used before. This research ultimately introduces a conceptual 4D space-time diagram with a relation between the current physical situation and a growing number of 3D animated models over time.
\end{abstract}

Keywords: Animated Spatial Time Machine (AniSTMa); co-creation; gamification; 4D web; cultural heritage; 3D modelling; parallel virtual universe; Transmedia Storytelling; VR/AR/XR; e-participation

\section{Introduction}

In the 4th century BCE, Plato played with dimensions in the "Allegory of the Cave", while in "Flatland, a romance of many dimensions", Abbott dreamed about 4D in his novel of 1884 [1,2]. Queen sang in 1975, "Is this the real life? Is this just fantasy?" in "Bohemian Rhapsody", one of the world's most exciting pop songs ever, and in 1997, the theoretical physician Kaku explained why the multiverse counts 11 dimensions [3,4]. Dreaming in and about three and more dimensions in the continuum between reality and virtuality was not new in the 21st century. It is only since the last two decades that digital graphics' development made it possible to use 3D city models for visualisation and nonvisualisation (e.g., solar energy potential on roofs) [5]. Since the beginning of the 21st century, it is possible to model large urban environments, including complete and realistic semantic descriptions of urban scenes [6]. To this end, different types of equipment are used, such as $3 \mathrm{D}$ lidar scanners (air, mobile, terrestrial, hand) and satellites, but also large format aerial photogrammetric data sets and oblique images [7]. Usually, 3D city models relate to the real world's most recent situation at the moment of production [8]. If time is mostly 
seen as the 4th dimension, different authors agree to see the spatial resolution as the 5 th dimension, also known as the Level Of Detail (LOD) [9,10]. Adding the dimension "time" to a 3D city model implies looking to the future and the past. Three-dimensional models from urban planners, (landscape) architects and public designers can integrate future developments. Four-dimensional Building Information Modelling (BIM) is a helpful tool to achieve this goal, as it combines the $3 \mathrm{D}$ city models of the existing urban structures with future plans $[11,12]$.

The digital reconstruction of the disappeared past in a $4 \mathrm{D}$ environment, which is the focus of this article, is more complicated than integrating future spatial developments. For some old locations, sketches, plans and drawings (dating back to the 10th and 11th centuries) are available, as Fritsch mentioned [13]. However, for the most demolished culturally rich architecture, old paintings, sketches, literature and archaeological data are sometimes scarce but, above all, diverse (not covering time and space) [14,15]. There are two methods to digitally reconstruct lost city environments: manual and (semi-)automatic. Manual reconstructions are expensive iterative processes due to the need to correctly interpret the historical sources and discussions between archaeologists, historians and 3D modellers [16]. (Semi-)Automatic methods are available to build reconstructions from old maps on urban history [17]. Procedural Modelling (PM) might be an automated 3D methodology for architectural historians by changing parameters instead of manual drawing [18]. Artificial Intelligence (AI), Machine Learning (ML) and Deep Learning (DL) will prove to be helpful in the future, but this is not the scope of this research [19].

Since manual reconstructions are expensive and (semi-)automatic reconstructions are not accessible to everyone, exploring a variant of the manual method is interesting. The question is whether e-collaboration with citizens could help to reconstruct the lost historical architecture in their neighbourhood. How and by means of which actions could we motivate citizens to use 3D co-creation as the power of crowdsourcing in reconstruction and make the results available for education, fun and other (professional) applications? Citizen science, a form of collaboration in which residents participate in scientific research, is a growing research topic [20]. In Participatory GIS (PGIS), citizens work together on future development, mainly with geographic 2D data [21]. In participatory 3D modelling (P3DM), citizens participate in making digital 3D models or maquettes [22]. Digital 3D co-creation goes a step further, as it implies that people are working together on 3D models. Already in 2010, co-creative visualisation in a virtual world was tested online in "Second Life", in which more than 400 MBA students participated [23]. The results proved that 3D co-creation might be deployable for reconstructions if not funded for expert rebuilding.

In 2016, the City of Ghent (Belgium) started a project to involve citizens in the digital $3 \mathrm{D}$ reconstruction of their environment's past (in co-creation, without funds). Ghent is a pioneer in 3D city modelling. It started with 3D modelling for urban design, planning and city renewal during the 1980s. In the 1990s, they performed experiments with Virtual Reality (VR) and, a few years later, with 3D GIS and digital drawing participation processes. Ghent received different national awards for combining co-creation and innovation in 3D city modelling. In a co-creative project promoting "Dream with us in 3D!", dozens of citizens joined workshops to learn 3D drawing or writing code; some of them were interested in reconstructing the city's lost historical architecture. After co-creative 3D modelling and gamification, the results became accessible in a $4 \mathrm{D}$ web environment. The 4D web environment became part of Transmedia Storytelling (TS): an integral process of combining various media in which each medium makes its unique contribution to the unfolding story, creating a unified and coordinated entertainment experience [24]. For this co-creation, all kinds of media were used. Combining real and virtual objects was already explored by Milgram as Mixed Reality (MR) in the virtual continuum of 1994 [25].

This experiment's descriptive research shows the new possibilities of combining free 3D software, 3D animation in game engines and 4D interactive online completed by nonspecialists. Since Morello mentioned the city as a "time machine" in 1999, city time machines have mainly been limited to collected digitised records in databases or some static 
$3 \mathrm{D}$ models representing the past $[26,27]$. A 3D city model, including time as dimension and featuring moving objects, could be appointed as an "Animated Spatial Time Machine" (AniSTMa). To the best of our knowledge, this term has never been used before.

Section 2 of this paper examines related work on the reconstruction of the past, the possibilities of 3D co-creative e-collaboration and e-participatory processes, 3D gamification, $4 \mathrm{D}$ web publishing and Transmedia Storytelling (TS). In Section 3, the possibilities from the Ghent case are investigated to enable online animated reconstructions by 3D co-creative processes. Finally, in Section 4, recommendations to create a framework to support 3D co-creative projects for historical reconstructions are mentioned. This descriptive research results in the launch of a new $4 \mathrm{D}$ space-time diagram, the Bagpipes Model (BP-M), showing the potential evolution of the animated 3D models' availability in space and time in relation to the physical world's actual situation. The research results testify to the enthusiasm of citizens to historical reconstructions of their city due to a holistic approach. Providing a framework to work in can help streamline the organisation and data, as more 3D models will become available for different periods.

\section{Related Work}

The process descriptive research is situated at the intersection of five topics outlined in this chapter: 3D modelling for a 4D Animated Spatial Time Machine (AniSTMa), 3D co-creation and e-participation, 3D animation and 3D gamification, 4D interactive web publishing and Transmedia Storytelling (TS). The integration of these disciplines shows interdisciplinary and animated possibilities to bring the past to life through 3D co-creation.

\subsection{Three-Dimensional Modelling for a 4D Animated Spatial Time Machine (AniSTMa) Development}

Various software environments are available to create 3D city models for geography, planning and building: Computer-Aided Design (CAD), Geographic Information Systems (GIS) and Building Information Modelling (BIM). In view of the complexity and considerable effort to learn this software, most users only focus on one of those [28,29]. When dealing with 3D city models using GIS, there is still a lack of Graphical User Interfaces (GUI), so inexperienced users are not able to create decent 3D maps [30]. Three-dimensional visualizing is more complicated than $2 \mathrm{D}$, because objects closer to the observer should be displayed in more detail [31]. The world is continuously changing. These changes should be analysed by means of different spatial and temporal attributes, preferably integrated into a Continuous Spatiotemporal Model (CSTM) [32]. To this end, higher-dimensional data models should be used (uniting space, time and scale) to support the spatiotemporal analyses and modelling [33]. Time is not always seen as the 4th dimension; Ohori et al. promote the Level Of Detail (LOD) as the 4th dimension [34]. By seeing time and scale as higher dimensions, changes in 3D objects or various LOD could be integrated [35]. Time must ideally be part of the higher dimensionality and is not only an attribute of the Euclidean 3D space [36].

If interdisciplinary studies on urban history examine the development of methods and technologies for $4 \mathrm{D}$ representation [37], historical photos and photogrammetry could be valuable techniques to rebuild the lost reality from roughly the past 100 years $[38,39]$. Even when different data sources (floor plans, sections, images) are combined, the demolished buildings' reconstruction is still tricky [40,41]. The integration of minor archaeological artefacts and larger entities (buildings and landscape) goes smoothly, sometimes aided by crowdsourced images of lost cultural heritage [42,43]. Due to earlier research, it is possible to derive a 3D model from one photo in free software such as Sketchup $[44,45]$. To avoid data chaos, 3D models of reconstructions need to be structured. CityGML is a valid exchange format with good data interoperability in 3D city modelling, helpful in historical reconstructions [46]. CityGML also plays a role in the valorisation, conservation and management of the existing cultural heritage but requires additional expertise, which $3 \mathrm{D}$ modellers (without knowledge of GIS) do not always have [47]. Heritage BIM (H-BIM) is a professional instrument to manage and conserve historical sites [48]. In order to generate a 
series of buildings with the same architectural typology, Procedural Modelling (PM) helps to reconstruct and to solve the Levels Of Detail (LOD) problems automatically [49,50]. PM could deal with the uncertainties on the correctness of the original forms of cultural heritage by displaying variants in the same building typology; City engine is such a helpful tool [51]. Regarding the use of Artificial Intelligence (AI), the automatic classification of point clouds using Machine Learning (ML) has been investigated during the last decade [52]. It could generate a 3D city model with a similar building typology starting from a photo of a street pattern only by changing the parameters [53].

A fascinating science project is Rome Reborn [54]. Since 1997, community members make apps and videos of the ancient city as it appeared in $320 \mathrm{CE}$. In addition, a 3D scan of the old maquette "Plastico di Roma Antica" $(16 \times 17.4 \mathrm{~m})$ has been added [45]. The 3D scanning of old physical models, as described by Kersten et al., is also a means of integrating the past in a 4D city model [55]. The development of a 4D mirror world is the objective of the Time Machine project, which the European Commission has selected as one of the six most critical large-scale research initiatives for Europe's future in 2019 [56].

The present paper's research focuses on the use of 3D CAD software by citizens, converting it into 4D GIS online in an Animated Spatial Time Machine (AniSTMa).

\subsection{Three-Dimensional Co-Creation and e-Participation}

Images and data visualisation have become increasingly influential in opinion forming and decision making in a mediatised world without language barriers via the internet and social media, because they speak to the mind and to the heart [57]. Geoparticipation can involve many people and increases the sense of belonging to a group [58]. Ideally, spatial e-participation should involve citizens through a 3D web geoportal at any time, anonymously and from any place, using a simple tool [59]. Participation in an urban evolution understanding will be possible in a multidimensional web-GIS approach [60]. When using online streaming 3D-GIS in e-participation, the lack of detail of 3D visualisations might be a limitation [61]. Already in 2006, as a result of an Interreg IIIB North-West Europe project, Counsell presented an open standard web VR approach to enable citizens to view, analyse and communicate [62]. With the iterative use of a mix of 3D participation tools, democratic public engagement in the decision making process increases and reduces barriers among the stakeholders [63]. The use of 3D content could be beneficial to all parties (planners, architects, governments and the public), with gamified artefacts appealing to the hard-to-reach groups [64]. In the 3D participatory processes, Participatory Design Methods are also an opportunity [65]. In 2013, Brovelli posited he was the first to implement a fully participatory framework that enabled 3D data visualisation [66].

Digital Twins offer new opportunities for convincing citizens to participate. A digital twin is, in origin, a digital copy of a physical object, and for some years, 3D models of cities have also been called "Digital Twins". It implies the embedding of all kinds of registers and databases, even real-time sensor data of the city needed for forecasts and a good policy $[67,68]$. Geosocial tagging for co-creating cultural values through storytelling in geography is also an example [69]. The use of information and communication technology to optimize the knowledge, management and sharing of information in cities, focusing on a higher quality of government services, leads to Smart Cities. The quadruple helix actors' involvement (citizens, government, industry and research) is crucial for cocreation, combining intelligence by means of digital platforms. Thus, Smart Cities emerge and evolve [70].

Co-creation is theoretically creation through interaction. However, Ramaswamy et al. formulate this as follows: "Co-creation is an enactment of interactional creation across interactive system environments (afforded by interactive platforms), entailing agency engagements and structuring organisations" [71]. Focusing on 3D co-creation, free drawing programs such as Sketchup were already proposed as useful for the nonspecialist in 2010 [72]. In 2017, citizen design science (a combination of citizen science and citizen design) was proposed by Mueller et al. as a strategy for co-creative urban design focusing 
on their neighbourhood [73]. In cultural heritage, co-creation provides value through multitechnology such as VR/AR and 3D printing [74,75]. Archaeology could show the core of co-creation by letting go of control and by being guided by the masses in the digital preservation of archaeological objects [76]. In "The art of Crowd dreaming", a methodology has been proven to digitise cultural heritage as cross-generational digital monuments in a co-creative living lab [77]. Finally, Building Information Modelling (BIM) is a co-creative process for professionals. It enables collaboration between various construction partners. After finishing the building, BIM remains in use in facility management during the lifetime of a building. The benefits of co-creation in the design process are essential here [78].

\subsection{Three-Dimensional Animation and Gamification}

Digital 3D games are made for fun but might also serve as a social, educational tool, such as changing human behaviour or solving environmental problems $[79,80]$. They support the city development and education about the past. Gamification motivates cooperation creativity, thinking about spatial development and could also serve as a crowdsourcing strategy to enrich datasets in Smart Cities [81-83]. In the Volunteered Geographic Information (VGI), the relation between the gamification and individuals' motivation to collect spatial data is challenging [84]. A 3D gamified interface generates more proximity and a sense of presence than the 2D approach [85]. Due to this, Mat et al. saw great potential in the three most popular 3D game engines: CryEngine (2004), Unity 3D (2005) and Unreal (2009) in order to make GIS data usable [86]. Unity has become famous. It allows an improvement in spatial thinking and orientation thanks to a strong sense of presence as in the real world [87]. Unfortunately, Unity does not support the coordinate systems of the 3D city models, but Mapbox for Unity solves this shortage [88-90]. Game development is a fast-growing business, so 3D modelling software tries to be part of that game, such as open source Blender3D with an embedded game engine and Autodesk promoting its opportunity for games [91-93]. In a gamification-based environment, a significant difference is noticeable between the gamers and nongamers [94]. A long download time using game engines for online 3D city models is a disadvantage [95].

Game engines allow recreation of historical scenes in a time machine with animated virtual 3D characters [96]. With historical clothing, facial expressions, gestures and postures, historical characters can visually convey a multitude of information in a vivid, engaging way [97]. The resuscitation of the past social life is possible through 3D animated character modelling and historical scenes' reconstruction [98]. Three-dimensional co-creative gamification is an appreciated tool for dynamic animated evocations. Game engines are a step forwards in using VR/AR/XR. More and more applications with VR on 3D city models are described $[99,100]$. Even AR is applied for 3D city models, but mostly without moving objects [101]. Regarding the animated models, game engines are primarily used [102].

\subsection{Three-Dimensional/Four-Dimensional Interactive Web Publishing}

For a long time, 3D and 4D web viewers have been used for all kinds of applications and, more recently, for 3D city models, as well. The separate 3D models of city objects, e.g., street furniture or cultural heritage objects, could be found in all scales and on all themes online. Since the late 1980s, websites have existed with a growing number of 3D model collections, allowing designers to display and sell their 3D designs on the internet [103]. In 2010, the development of web-based VR applications in the field of cultural heritage was a direct result of the advance in surveying and internet-related technology [104]. In 2015, the number of online 3D models exceeded the four million (more than three million for free), with online 3D driven by global digital transformation trends in BIM, VR/AR, Industry 4.0 and robotisation [105]. By offering 3D models via Web3D technologies, virtual educational environments have become cheaper and more accessible [106]. With an object-oriented approach in historical research and visualisation, for example, it is helpful that 3D models are available online (for the archaeological documentation) [107]. 
The streaming of $3 \mathrm{D}$ city models is more complex than in $2 \mathrm{D}$ and requires a lot of data transmission. In 2015, Krämer concluded that none of the open-source WebGL frameworks (X3DOM, three.js and Cesium) covered all aspects and requirements for 3D streaming [108]. Open-source CesiumJS appears to be a suitable tool for visualizing the 3D city model online [109]. The Cesium Virtual Globe is an open-source Javascript library (developed with HTML5 and WebGL), suitable for the time-dynamic 3D visualisation and easy integration of various libraries [110]. For streaming 2D maps, the Web Map Service (WMS) and Web Feature Services (WFS) are utilised. Virtual 3D globes are comfortable to use a more effective contextuality of the displayed phenomena over time, so interactively, $4 \mathrm{D}$ online is the aim [111]. Four-dimensional web browsers act as alternative repositories for the historical images, floor and building plans of cultural heritage objects, used in an interactive 2D web visualisation [112,113]. However, streaming more than 2D graphic models is still a problem, so hardware performance and fast data transfer should enable an online visualisation of large, high-resolution 3D models [114]. The search for a more optimal streaming of 3D models continues, whereby the use of 3D Tiles could become the streaming standard [115]. Disseminating the methodological documentation for authors of 3D heritage visualisation is generally minimal or absent [116]. The GIS-based functionalities (combined with motion effects on 3D animated moving objects) are not widely supported by web applications or development frameworks [117]. The conclusion is that 3D web technology offers possibilities for online interactive use through the combination of 3D modelling viewer software (including spatial analysing functionalities) and 3D animation using game engines.

\subsection{Transmedia and Interactive Storytelling}

In 2003, Jenkins introduced the term Transmedia Storytelling (TS), an interactive learning experience with different fictional elements, levels and distribution channels, increasing the engagement and optimising the understanding of essential topics [118,119]. Telling interactive stories in a visualisation and animation concept creates a higher level of user interaction in a virtual environment [120]. When substantial changes occur in the story, the disadvantage is that the production costs increase inconsistently, because more than one medium has to be adapted, so it can be difficult to finance without more funds $[119,121]$. Nevertheless, the possibilities of TS are growing thanks to the new digital developments [122]. In this research, TS is implemented during the co-creation process.

\section{Materials and Methods}

This chapter describes the process of a co-creative 3D modelling case in the City of Ghent. Firstly, the birth of the co-creative workshops is described. After that, a list of the conditions to bring this concept to a good result is mapped out: historical and open 3D data, soft- and hardware and 4D web architecture. Attention was paid to the 3D animation, gamification and TS. A detailed description of the subcases was mentioned, and finally, a new space-time diagram is presented to manage the (animated) 3D models.

\subsection{The Case Study of Ghent}

The medieval City of Ghent (Belgium) was the 3rd biggest North-western European city after Paris and London, larger than Amsterdam and Brussels. Today, Ghent counts approximately 260,000 inhabitants. In the 1980s, Ghent started applying CAD, GIS and 3D modelling for the urban planning and city development. In the 1990s, Ghent began using VR with a Head-Mounted Display (HMD). In 2000, it installed a homemade 3D C.A.V.E. (Computer Aided Virtual Environment), and the experiments with 3D GIS date back to 2003. In 2008, Ghent was the first Belgian city to introduce a 3D Team to develop and coordinate 3D applications for all city departments. Thanks to years of inventive 3D (re)search, they have received funding from the EFRD innovation program (European Fund for Regional Development) from 2009 to 2015. In 2009, the inner city was Lidar airborne 3D scanned and vectorised into a big-scaled 3D dataset. In 2014, the whole city 
became available in a LOD2 CityGML-format. Different professional projects were grafted on this 3D model. The 3D Team organised dozens of interactive demos with 3D scanners, 3D processing, 3D modelling, 3D animation, 3D printing and VR/AR. Citizens, students, tourists and foreign guests worldwide visited "Ghent in 3D". Since 2015, there was no budget left to build new applications on the 3D datasets (after the EFRD funding). Ghent is not the only city with a lack of financial means to update the 3D city model. Due to this reason, the idea arose to focus on co-creative 3D modelling (www.space-times.org accessed on 2 May 2021).

\subsection{Workshops Co-Creation}

During the EFRD project in 2012, a children's competition called "My house, my dream" was organised (Figure 1) [123]. About 100 children designed their dream house through different nondigital media. Ten selected children attended a 3D workshop week together with one MA student in architecture connected to each child. While children participated in the architecture sessions, living in the city and 3D modelling, the architectural students transformed each child's dream house idea into a digital 3D model. After the workshop week, the 3D city model included ten newly designed virtual houses, to the parents' and the mayor's enthusiasm. The latter demonstrated that children's involvement in thinking about the city's future using 3D could inspire and engage them in the urban development participation [124]. The project's success led to new ideas, showing architects an opportunity to put their projects in the 3D city model. As a result, Ghent decided to open 3D data online for architects and other actors (as the first Belgian city).

Inspired by the previous project, the "3D city game Ghent" started as a new co-creation in 2016. Citizens were invited to use the 3D open data to draw new ideas in 3D for their environment (Figure 2a). Some 3D ideas could inspire the city government to be realised in the real world. If not, the unrealised dreamed projects could remain in a virtual exhibition with ideas regarding the city's future in 3D online or VR/AR. The project attracted all age categories from 7 to 80 years old (Figure 2b). Hundreds of residents gathered around different topics in the first demystification sessions. Participants got a short introduction on digital 3D drawing, orchestrated by the 3D experts of the City of Ghent. During the following sessions, citizens with more experience in 3D modelling began to show the starters how to draw in 3D. After the introduction of a 3D game engine, combined with demystification sessions in the tools' programming, some participants learned to write code (Figure 2c). The ICT partner of the city offered support in code initiations, and ICT internship students were called in to teach. It became a unique collaboration between citizens and civil servants. Most people participated without expertise. They associated with experts in the group. Others only visited to take a look, but real all-rounders also came along, engaging in the aspects of 3D modelling, writing code and storytelling. Sessions were organised in schools and residential care centres, and a prospection took place to involve sick people from Ghent's university hospital. Participants dreaming about the future drew 3D robots in science fiction style. Several residents gathered to reconstruct the past. The co-creation involvement was included in a logo design competition. 


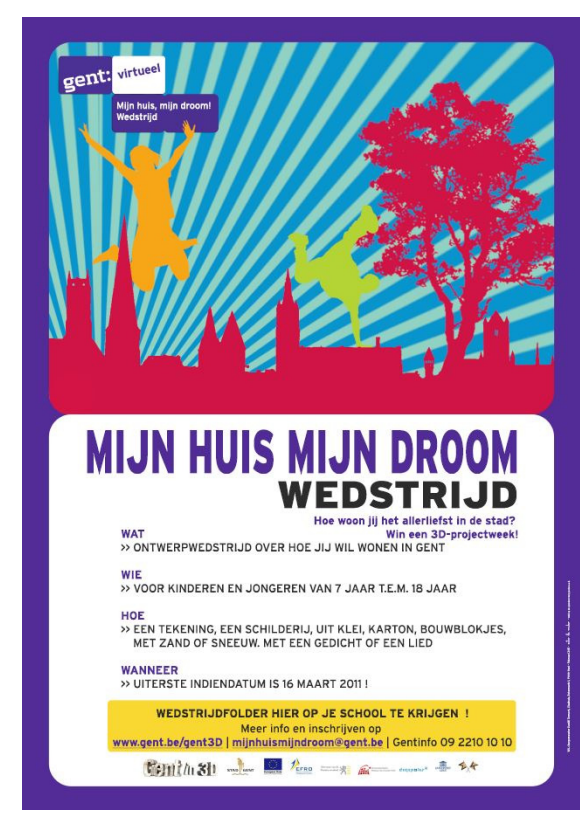

(a)

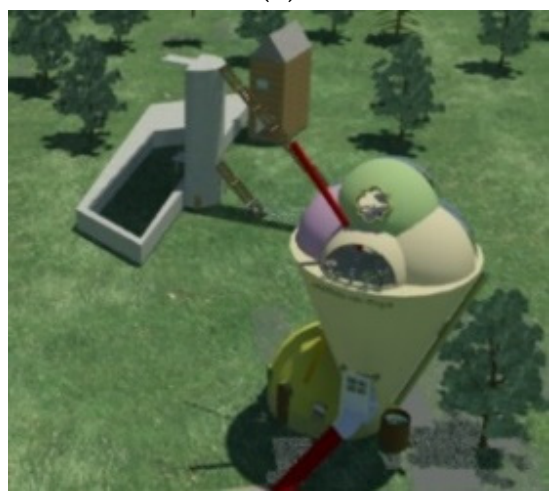

(c)

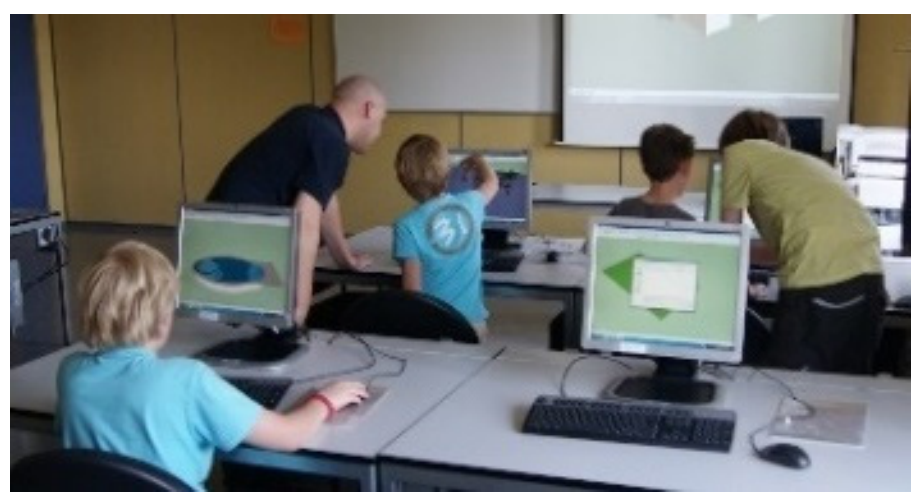

(b)

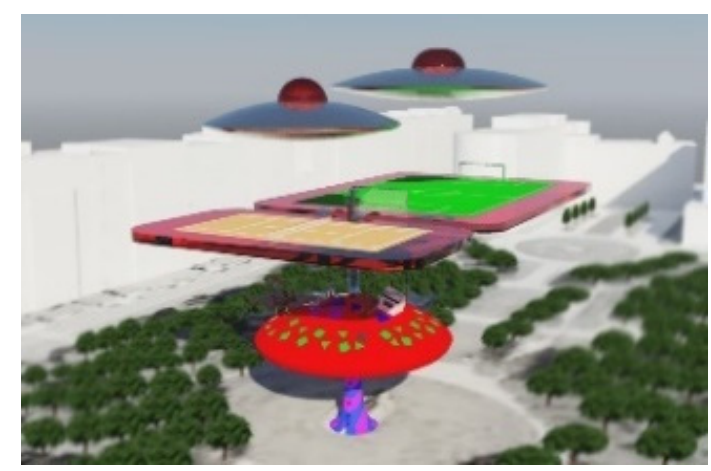

(d)

Figure 1. "My house, my dream", Ghent, April 2012: (a) Competition flyer; (b) Children in a 3D workshop; (c) A 3D ice cream house integrated into a park; (d) A virtual flying playfield above a dreamed 3D mushroom house.

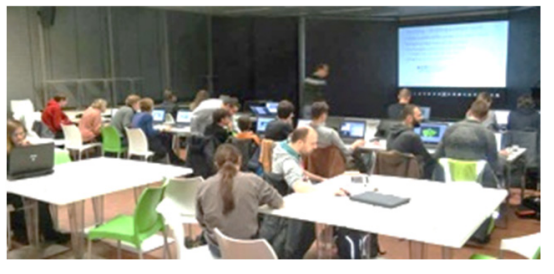

(a)

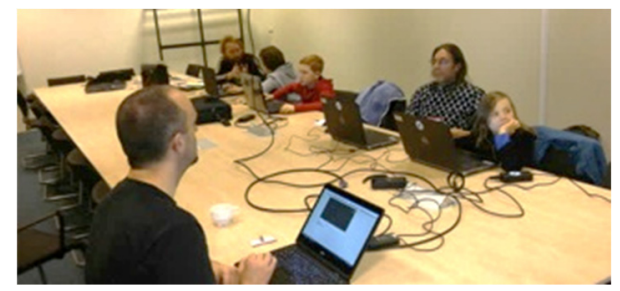

(b)

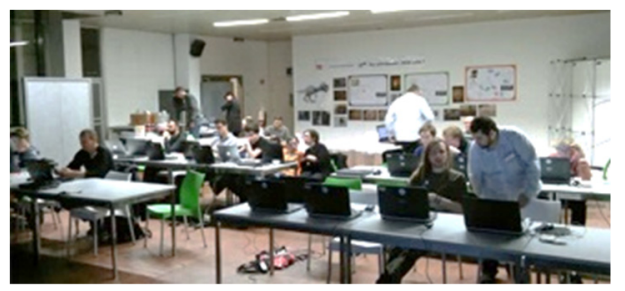

(c)

Figure 2. Three-dimensional City game Ghent, 2016-2021: (a) Instruction session; (b) Young and old together; (c) Cocreative workshop.

The project's communication began with a call in the city magazine. The Ghent website and social media provided information, as well [125]. The call centre of the City of Ghent registered the workshops' participation. Meetup.com was employed to communicate the sessions' frequency [126]. COVID-19 made the physical workshops from March 2020 onwards impossible until a restart of the online meetings with MS Teams was enabled. The combination of co-creation and innovation using gamification was granted an internal city 
award, the Geospatial award for the best Belgian Geoproject and the e-Gov innovation award for the most innovative digital administration project in Belgium in 2019.

\subsection{Analysing the Lost Historical Architecture and City Environment}

A group of participants wanted to revive the wealthy city's history of the demolished (or destroyed) culturally rich architecture. The city archives were visited to explore the historical drawings, sketches, paintings and books in order to reconstruct the past (Figure 3). Co-creative citizens sometimes bought a book or went to different libraries to search for old sources. The collaboration with the Ghent archaeological and cultural heritage administration resulted in well-made digital 3D reconstructions (see Section 3.9.1).

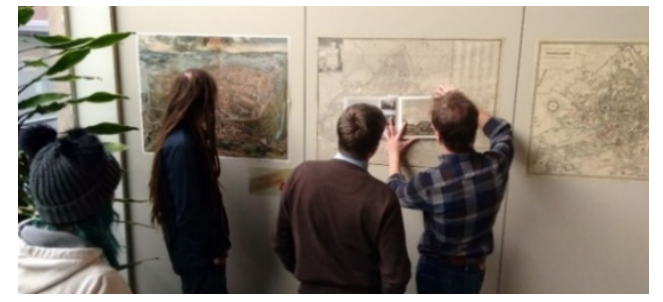

(a)

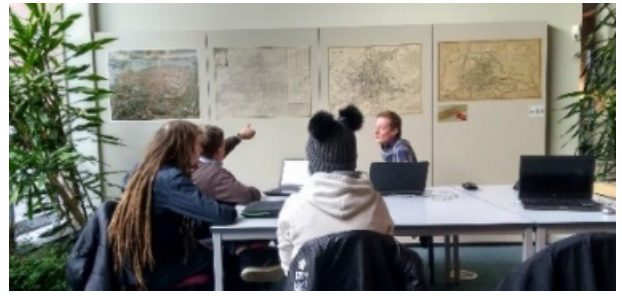

(b)

Figure 3. Co-creation in the city archives of Ghent, 7 November 2017: (a) Information session in the archives; (b) Discussion.

The lack of architectural drawings on the disappeared buildings is a problem for the digital reconstruction. Sometimes, the software might offer a helping hand, even for nonprofessionals, with a "matched photo" functionality to create 3D models starting from only one 2D-perspective photo. A click on "match new photo" on the "camera" allows one to import a building image. A base point must be placed and the lines positioned to coincide with the facade surfaces' top and bottom lines. Immediately afterwards, this particular building could be drawn in 3D [127]. Given the rules for perspective and vanishing points, it is easy to generate two sides of a 3D building in more detail, but reconstructing the backside of a building, however, is guesswork that way. This technique was applied with Ghent oil painting of the 16th century (made by an unknown painter), reconstructing tiny houses (Figure 4). The next step in future 3D co-creation will include the use of parametric modelling so as to provide H-BIM libraries through the repetition of varying objects during specific periods [128]. More and more 3D models of architectural objects from past centuries (drawn by citizens and online 3D stores) will become available. A particular task is to catalogue all those building parts in digital 3D libraries and $\mathrm{H}-$ BIM environments. Changing the parameters instead of drawing in H-BIM will simplify the process.

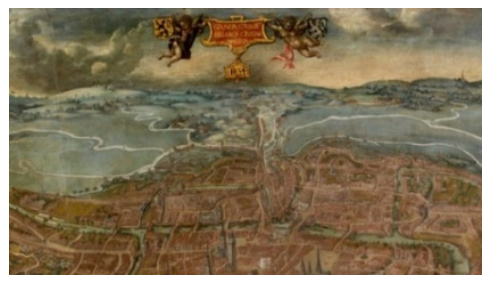

(a)

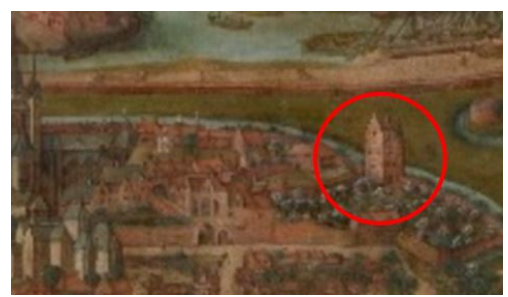

(b)

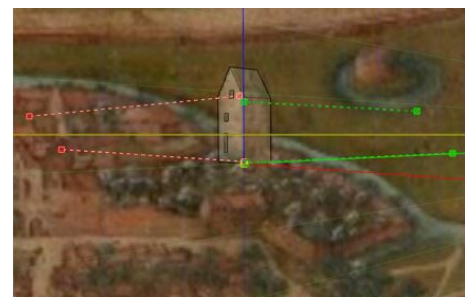

(c)

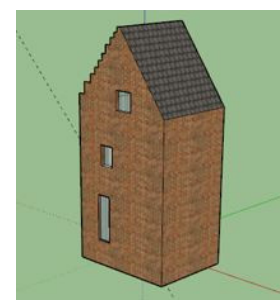

(d)

Figure 4. Photo matching: (a) Oil painting; (b) Detail of the painting; (c) Matched photo; (d) 3D model after matching.

\subsection{Soft- and Hardware}

The starting 3D modellers with no experience obtained an initiation in Sketchup as well as easy and free 3D modelling software on the city administration laptops [129]. Some 
bought their laptop using specific 3D modelling software (Sketchup pro, Blender, 3D studio max, Z-brush, Cinema 4D). The programmers worked in C\# or JavaScript for Unity; some used Github to collaborate in code [130]. The storytellers (responsible for the scenario) came up with a story in MS Word. Slack was applied to keep (historical) information on 3D projects and Trello in order to manage the tasks [131,132]. The collaboration software PlasticSCM was employed to design and write code in the same project simultaneously [133]. The professional digital environment to work together on 3D drawings (BIM) was not utilised, because it was too difficult for nonprofessionals (and not for free). In the future, H-BIM will possibly be introduced for the individuals who will continue to work on this collaborative project, especially for the reconstruction of cultural heritage.

\subsection{Open 3D Data, 3D Data Models and 3D Data Exchange}

In 2015, the City of Ghent published open 3D data online, according to CityGML LOD2, in ZIP files with DWG and DXF format blocks of $1 \mathrm{~km}^{2}$, including buildings and relief ( 1 zip file $\left./ \mathrm{km}^{2}\right)$, without texture. These 3D datasets were also used in the workshops after the first initiation. The starting Sketchup users could quickly draw simple 3D objects without working in a 3D city model environment. With a Sketchup Pro license, they could import DWG files in Sketchup and save these as SKP files to pass on to other participants (Figure 5). Lessons were learned; a common mistake for new users was not paying attention to the faces' normals in 3D drawings, forcing more professional coaches to fix this. Some older participants had a hard time learning, but they continued, driven by interest and enthusiasm. The drawings were exported from Sketchup to a DAE format. After a quality check in 3DStudioMax by the experts, the files were transformed from the DAE files into 3DML files (in the 3D viewer) and into FBX (for the game engine Unity).

Open 3D data
Conversion in Sketchup pro
Export DAE in Sketchup
Check DAE in 3DSMAX
Terraexplorer
Import in Unity

Figure 5. Data exchange from the open 3D data over Sketchup to a 3D web viewer and Unity.

\subsection{Three-Dimensional Animation and 3D Gamification}

Producing a digital 3D game or gamification requires at least three profiles: 3D modellers, programmers and storytellers. Citizens took up these roles. Sketchup designs made by 3D citizens were imported into the 3D game engine Unity, but Blender and Cinema4D files were also added [86,134]. They started using assets from the Sketchup 3D warehouse and the Unity Asset Store to remodel the buildings' surroundings (trees, vegetation, street furniture, animals) [135]. The internship students helped the co-creative participants to animate the 3D models in movement poses in Z-brush, Blender and 3D Studio Max. The co-creative participants with minimal experience but an excellent drive for programming started to add code for animation. Implementing different gameplay activities triggered engagement: actions, search, puzzle and craft. The audio also received attention, because it is another higher dimension of a multidimensional game environment.

\subsection{Four-Dimensional Web: System Architecture}

In 2014, Ghent started with an online 3D viewer from Skylinesoft, the Terragate server and the Terraexplorer 3D viewer [136]. Besides the 3D data, WFS offered extra 2D geodata. The streaming was very slow, and the major drawback was to install a 3D viewer plugin on the user's computer, not very inviting for the average citizen user. The LOD2 3D city model's streaming on Google Earth (using the KML format) was also skipped as 
an alternative. Although KML is native to Google Earth, the results were heavy for the data exchange $[137,138]$. It took until 2020 to redevelop 3D online. A new server and Skylineglobe license were purchased in a more recent release (based on CesiumJs and optimised for the online 3D city modelling). The more recent Skylineglobe server and TerraExplorer are commercial products that combine the advantages of CesiumJs and the easy use of a 3D web environment without the need for coding knowledge. The Terra for Web (TE4Web) has a significant advantage, because the navigation starts from a URL without a plugin. A Quality Assurance (QA) server is available on the development site managed by the Ghentian 3D Team. The PRoduction (PR) server is immediately available via the internet. The ICT city partner, District09, hosts both.

Different datasets are managed by the server (Figure 6). The static 3D data are using the SkylineGlobe Server (SGS) (in green). Three-dimensional Unity WebGL Builds (in orange) are found in another folder. On the SGS, the basic terrain with aerial photos is hosted as a terrain database, called MPT file, next to the other 3D data: 3DML files (made in TerraExplorer pro converting the DAE files), 3D shp, 3D tiles and 3D scan data. Two-dimensional data files might be added by means of the WMS and WFS services. While the SGS manages the static 3D and 4D information, the animated scenes are available in the Unity WebGL Builds. These output data consist of one folder per project with an index file and two other folders (build and template data) automatically generated by Unity. Both are managed by the "Internet Information Services" (ISS) (in blue). Finally, a load balancer acts as a portal to the internet. This server enables the Animated Spatial Time Machine (AniSTMa), using two combined software environments, the 3D geoviewer software (with spatial analysing possibilities) and the online use of a game engine (with animation). The hyperlinks connect the WebGL builds' URLs to the 3D web service from Skylinesoft. At the beginning of 2021, the data formats GeoJSON and 3D Tiles were tested, because the cross-domain (and data transfer) problems should be solved in a more integrated way [138].

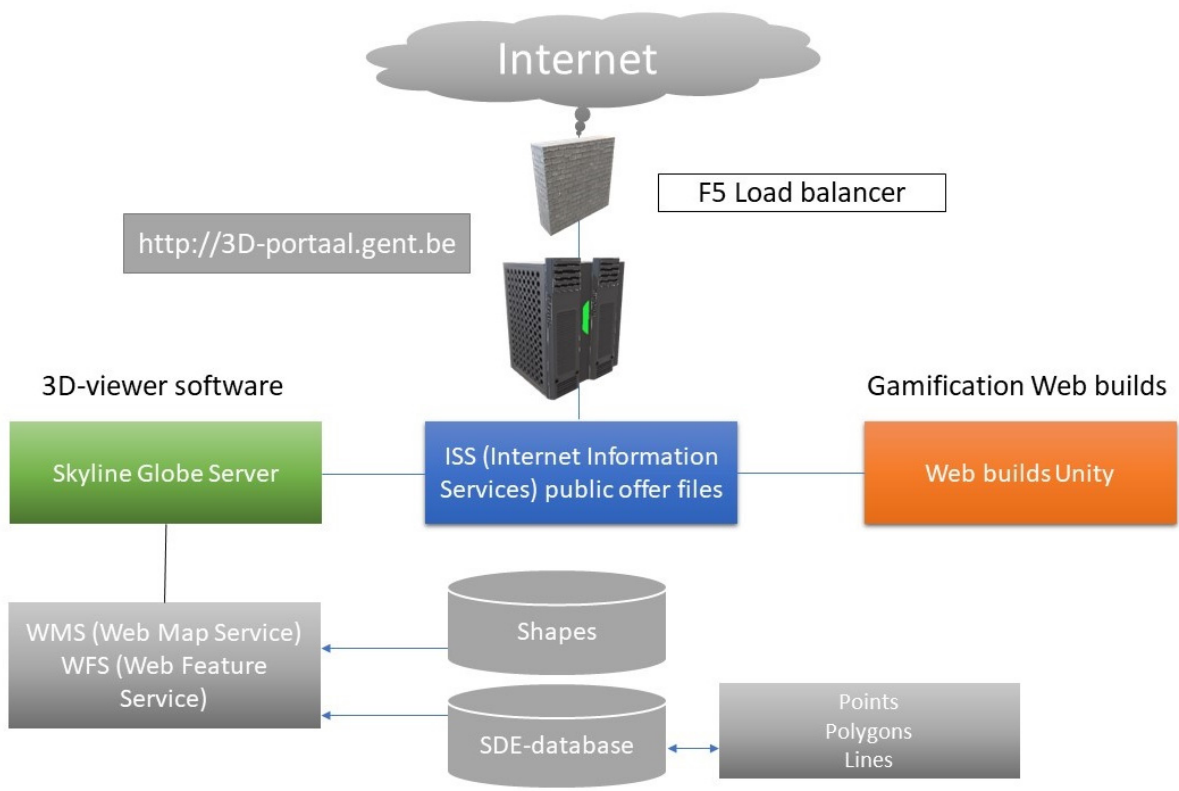

Figure 6. Configuration of the Skyline Globe and Unity Web build server.

\subsection{Transmedia Use and Storytelling: Hybrid Format (Digital/Physical)}

One of the necessary actors in game development or gamification is a storyteller. After translating the story into a 3D game engine (for fun or education), people's engagement will increase if they recognise the story in other media. A fundamental aspect of creating the interactivity dynamics and history personalisation includes the focus on the narrative and collaboration [139]. Using TS, the co-creative workshops did not end in the digital environment but in a hybrid output. The 3D reconstructions were 3D printed (Figure 7a), 
and information sessions about the production took place. Walks were organised in the surroundings of the demolished castle, and the local television commented. The description of 3D modelling is part of a book on the castle [140]. The transmedia view shows that someone has more empathy when identifying him/herself with the avatar, augmenting the story's effectiveness in this way [141]. Workshops were organised for children during which they redesigned old city castles, integrating medieval characters and playing with the shadows in the projection (Figure 7b). One of the 3D workshops' precursors was the co-creative design of new virtual walls for the Castle of the Counts during the light festival in 2012 (Figure 7c), executed after a citizen contest. It was a cheap action to promote cultural heritage creatively. TS is not always possible, because it is a question of funds [119]. However, it has become cheaper in co-creation. An extra motivation is that the knowledge of the city history is as necessary as the sensor data of the Smart Cities' actual situation.

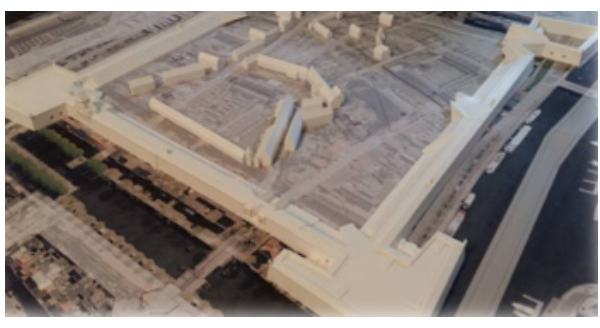

(a)

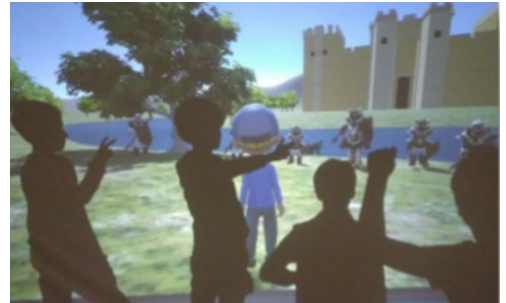

(b)

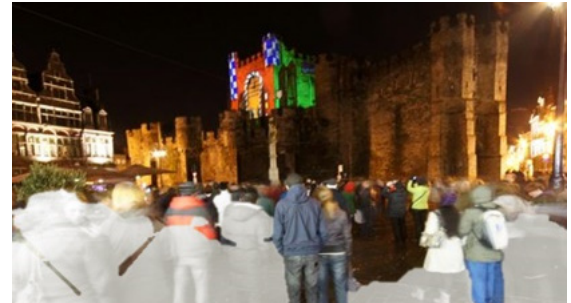

(c)

Figure 7. Transmedia Storytelling on the Ghent castle: (a) 3D printed Spanish castle; (b) Children playing in the projection; (c) New virtual walls for the Castle of the Counts, light festival Ghent, 2012.

The awareness grew that this 3D co-creative project could aid the interactive education. Transmedia supports new pedagogics, and interdisciplinary collaboration might solve complex educational problems [142]. TS should include people with visual or hearing impairments, so if transmedia production spans multiple media platforms, it is particularly suitable for these people in a shared storytelling world [121]. Figure 8 shows different 3D tools during the 3D co-creative project. Three-dimensional workshops and VR demos in the old Spanish castle's ruin (Figure 8b,c) and AR tests on the 3D co-creation models were performed (Figure 8d). An inventive look at the opportunities to combine the past and present delivered several excellent transmedia projects. In 2010, the renewed City Museum (STAM) presented a big 1/1000 scaled aerial photo of the city on a walkable floor. Above the city centre, a 3D printed model of the city centre $1 / 1000$ was available $(4.2 \mathrm{~m} \times 3.4 \mathrm{~m})$, presumably the largest printed 3D city model in Belgium in 2010 (Figure 8a). In 2020, the giant white 3D print changed from a "visual" to a tactile function, utilised for workshops with children. The co-creative 3D modellers applied this to fit their 3D printed historical reconstructions as an exercise to rebuild the old city (as a kind of TS). A 3D printed touchable maquette augments the tactile interaction, so blind people could participate in the Animated Spatial Time Machine (AniSTMa).

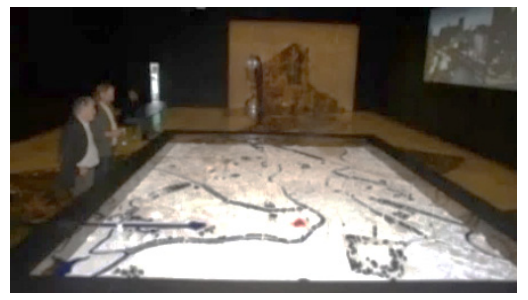

(a)

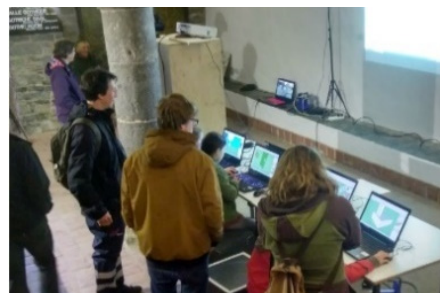

(b)

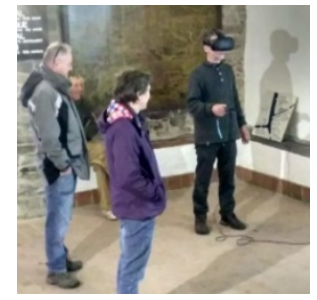

(c)

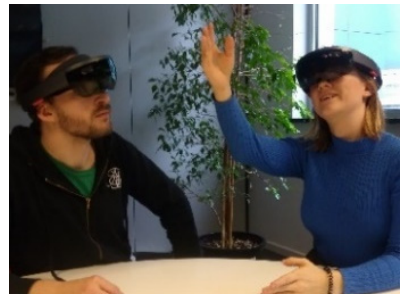

(d)

Figure 8. Transmedia Storytelling, City of Ghent: (a) 3D printed city centre at the STAM city museum of Ghent, 2010; (b) Workshop on the Heritage Day, Saint Bavo's Abbey, 28 April 2019; (c) VR demo idem; (d) AR with two Hololenses. 


\subsection{Examples}

In order to trigger other neighbourhoods, different co-creative 3D reconstruction cases were realised and spread all over the city (Figure 9).

The conceptual format was the same for all subcases, but the historical period was different. Differentiation was noticeable in the actors' sequences (Table 1). For the Princes' Court Castle, citizens completed the project without a considerable professional workers' input. In the "Wondelgem Dries" project, a citizen began, and academic researchers utilised the results afterwards, followed by further citizens' work. In the Spanish old castle project, citizens built on the existing 3D models made by professionals, and the city's 3D Team finished the project. In the 13th century project, linked to the Castle of the Counts, the 3D Team continued to build on the co-creative project, and citizens proceeded with it. In the South railway station and winter circus, professionals, trainees and residents cooperated in a hybrid configuration on the same 3D environment. External professionals continued with those 3D models by making new development designs for the old winter circus. Regardless of the projects' phasing, differences in emphasis still exist between the examples. The first example is described in detail (the others are discussed in minor detail).

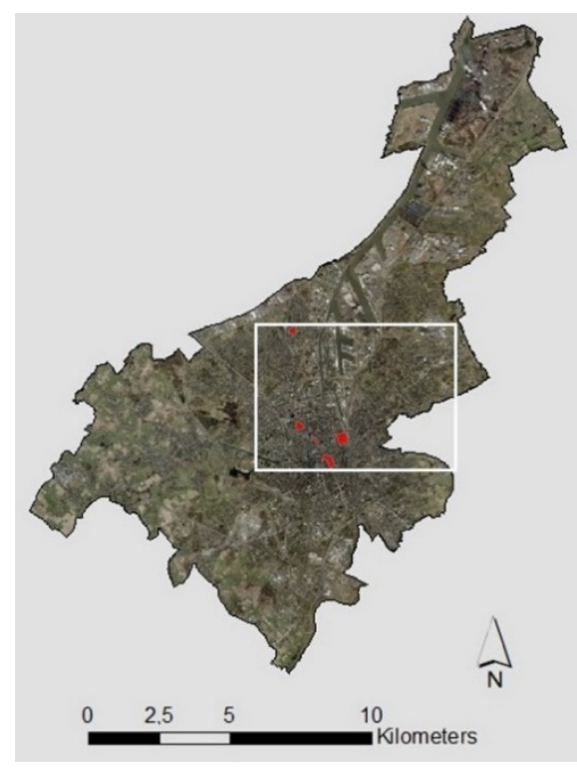

(a)

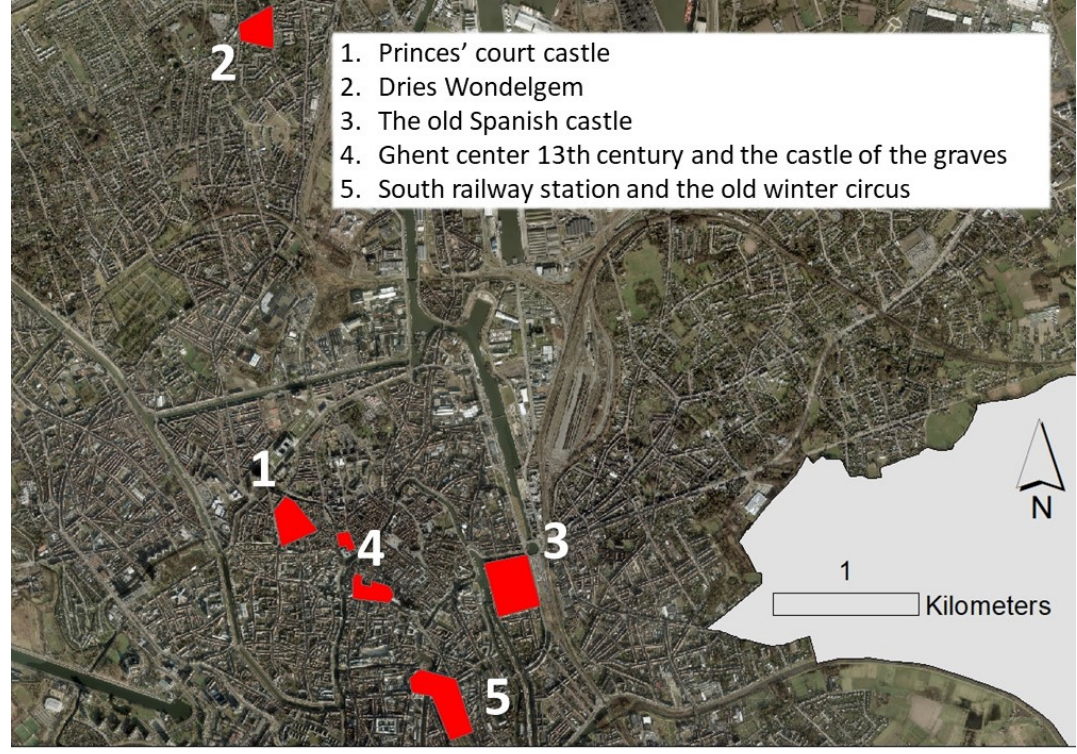

(b)

Figure 9. The location of some co-creative projects: (a) City of Ghent; (b) Situation of the projects (source: City of Ghent).

Table 1. Collaboration in the 3D cases, the timing of the input from the actors during various phases.

\begin{tabular}{|c|c|c|c|c|c|}
\hline Collaboration in the 3D Cases in Ghent & 2016 & 2018 & 2019 & 2020 & 2021 \\
\hline Princes' Court Castle & \multicolumn{5}{|c|}{ Co-creation } \\
\hline Wondelgem Dries & Co-creation & Acade & & & \\
\hline \multirow{2}{*}{ Old Spanish Castle } & External partner & & & & \\
\hline & & \multicolumn{4}{|c|}{ City of Ghent } \\
\hline \multirow{2}{*}{ Centre 13th century-Castle of the Counts } & Co-creation & & & & Co-creation \\
\hline & & \multicolumn{4}{|c|}{ City of Ghent } \\
\hline \multirow{3}{*}{ South railway station and winter circus } & \multicolumn{5}{|c|}{ Co-creation } \\
\hline & \multicolumn{5}{|c|}{ City of Ghent } \\
\hline & \multicolumn{5}{|c|}{ External partner } \\
\hline
\end{tabular}




\subsubsection{Princes' Court Castle}

The Princes' Court Castle in Ghent (Belgium) is the birthplace of Charles V (emperor of the Holy Roman Empire, Charles I, king of Spain, 1500-1558), whose personal union of the European and American territories labelled the first collection of realms "the empire on which the sun never sets" [143]. This castle was surrounded by water in the city centre during the 16th century (Figure 10a,b). In the 17th century, however, the castle's decline began, and most parts of the castle became demolished during the 18th century. In the Princes' Court Castle neighbourhood, the remnants are still visible on several walls of the existing buildings, and only the "dark gate" has remained so far (Figure 10c).

During co-creation, the different actors' roles became clearer: 3D modellers, code writers and storytellers, but, as in professional game development, other actors also appeared. These actors (participating for free) with different backgrounds are described.

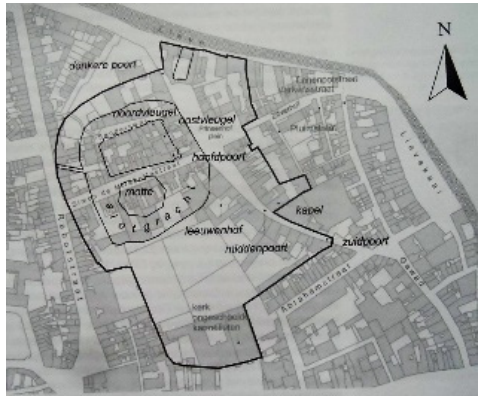

(a)

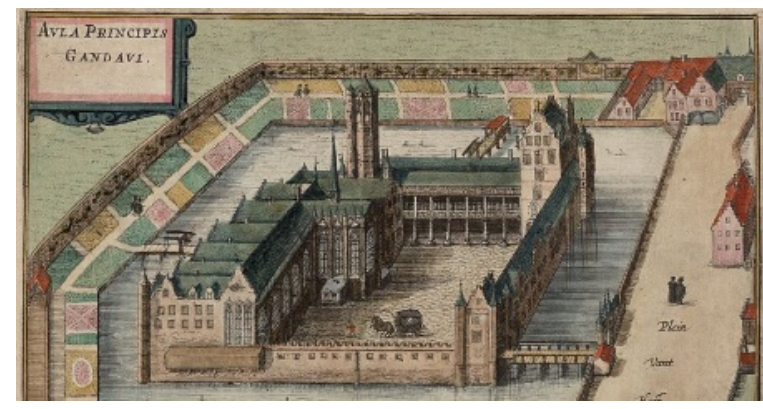

(b)

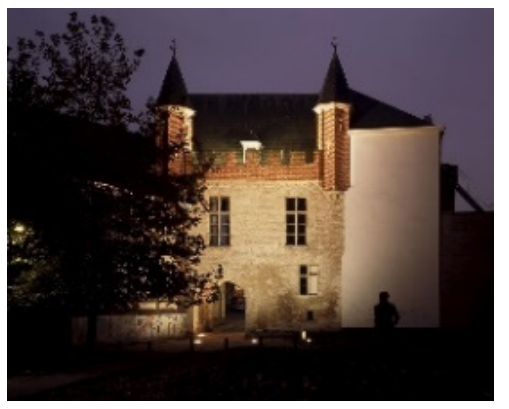

(c)

Figure 10. The old Princes' Court Castle: (a) Situation of the lost castle and domain; (b) Painting by Antonius Sanderus, 1641, Flandria Illustrata [144] (Open data: https:/ /ib.ugent.be/catalog/rug01\%3A000791673 accessed on 3 May 2021); (c) The still existing "Dark Gate", a remnant (the image: City of Ghent, Tourist service).

The "3D modeller" of this project was Dirk Van Wittenberghe, a retired military interested in old castles. Following a call launched in the city magazine to sign up for the co-creative sessions, he began an initiation in 3D drawing (without any experience). Soon, it became his passion to bring lost historical Ghent monuments back to life, starting with small projects and, finally, the Princes' Court Castle. A fascinating search through the Ghent city archive, image archive, cartographic databases and historical reference books arose until all pieces of the puzzle fitted. The archaeological data served as benchmarks to situate the model and to reconstruct the architecture (Figure 11). He detailed the demolished buildings in 3D without the skills of a professional modeller. The archaeologists and historical experts of the City of Ghent were truly impressed by his work.

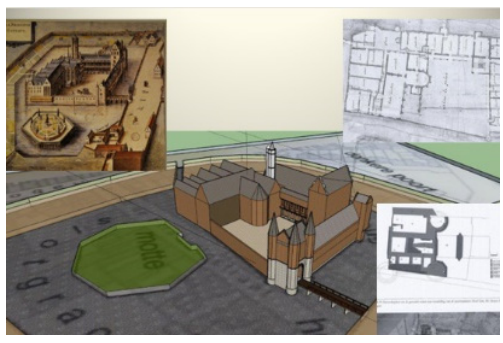

(a)

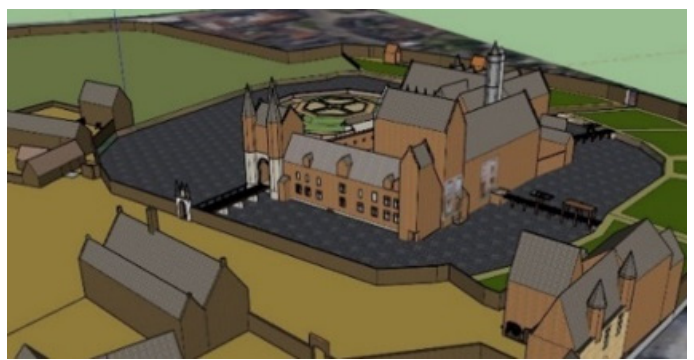

(b)

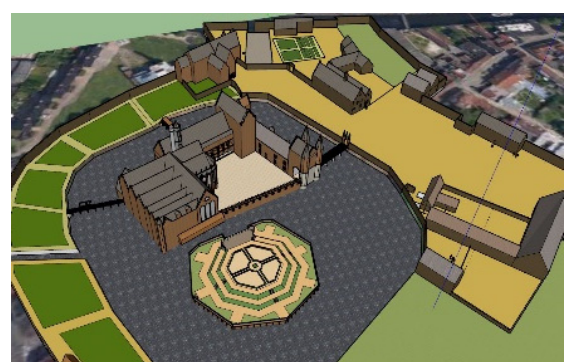

(c)

Figure 11. Reconstruction of Princes' Court Castle (D. Van Wittenberghe): (a) Historical research and SketchUp drawings; (b) More details in a Sketchup drawing; (c) Another view of the same basic model.

The "Code writer" of this project was Thomas Van Huffel, a design artist who learned writing in code. He integrated the castle in Unity and connected the internship students' 
work concerning an animated medieval festival and archery event, employing the Unity terrain function (Figure 12). The latter included a reliable 3D environment of the assumed historical context, the primary gamification setting, including the player actions.

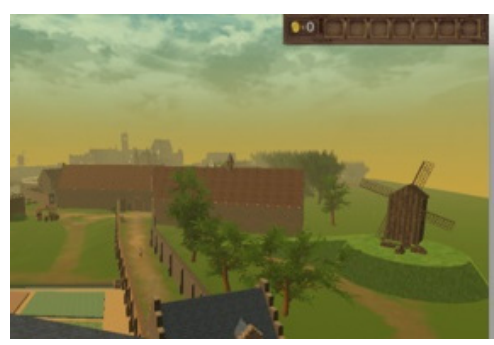

(a)

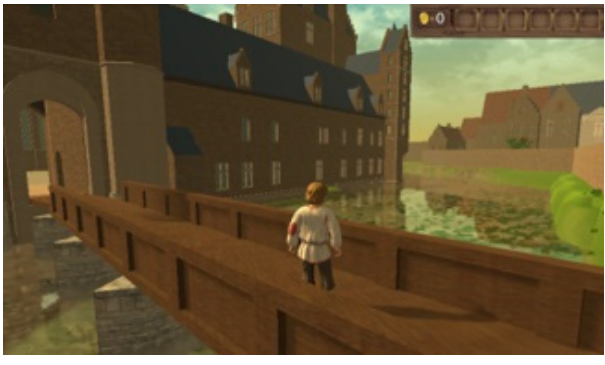

(b)

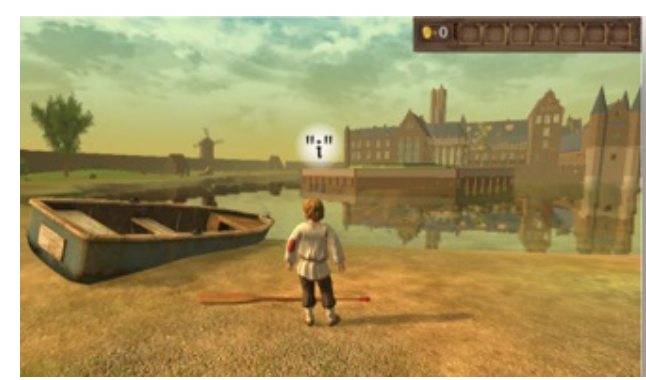

(c)

Figure 12. The animated environment of the castle domain in the 16th century using the terrain function in Unity: (a) Integration of the environment; (b) The Castle; (c) The moat and pond around the castle.

The "Storyteller" was Annie De Muynck, a resident with writing skills who came into contact with the project during "the digital week". The historical aspect and contact with people who knew a lot about history, code and designing programs fascinated her. She improved the scenario and game dialogues (Figure 13a,b). During the group sessions, fascinating discussions arose regarding the game dialogues, balancing real history and fantasy elements. Another citizen, Floor Loos, who possesses communication skills, managed the discussion about the format of the dialogues in the co-creative group using Google Docs, and Jo Luycx deployed his museum expertise (Figure 13c).

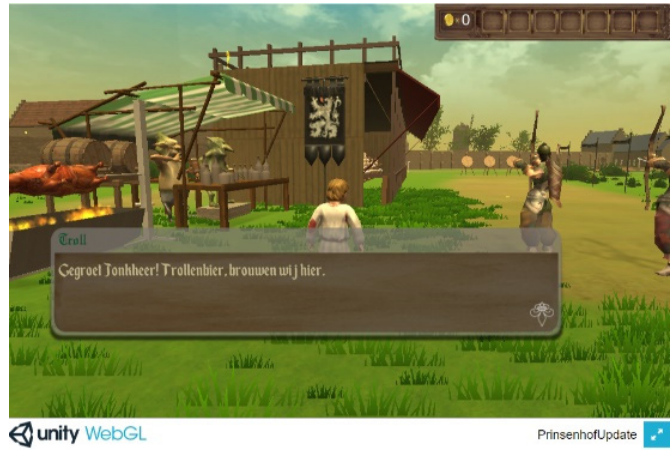

(a)

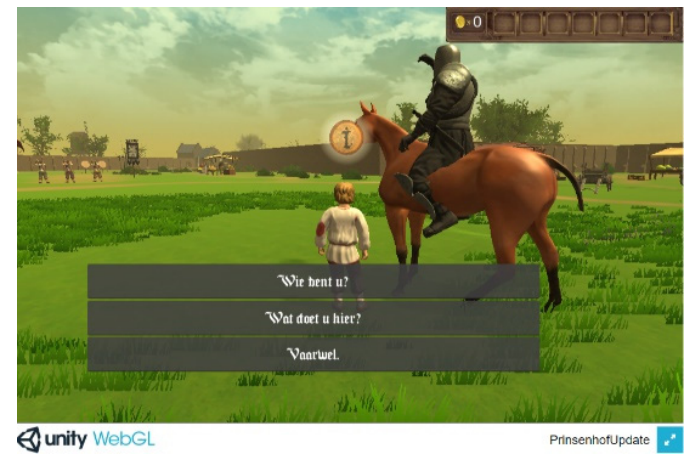

(b)

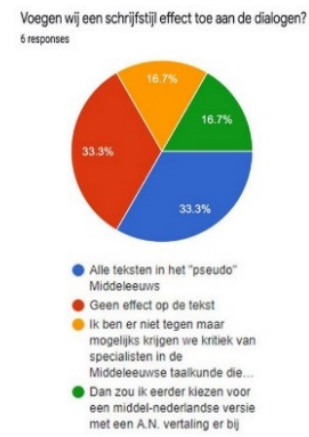

(c)

Figure 13. Dialogues: (a) Different scenes; (b) Multiple choice; (c) Dialect choice, a questionnaire in Google docs.

The musician Luc Callaert, a Ghentian singer-songwriter, took care of the "audio design". Born and raised in Ghent, he loves the city's rich history and felt proud to become the soundscape creator of this project. Luc combined his music and sounds with the animation of the medieval scene. Figure 14a shows a subscene with a troubadour, a virtual copy of Luc. He also made the "3D city game Ghent" project's primary game song.

The evocation of life in the 16th century castle was completed with various animated scenes. By means of the Unity shaders, a part of the castle burned again (Figure 14b), and 3D lions were revived in the "Lions court", as they lived there during the 16th century (Figure 14c). In order to show the opportunity to reuse the former 3D scenes in the game, a small snake game about "the noose barriers" (in Dutch: "Stroppendragers"), created earlier, was integrated. In the 16th century, dozens of Ghent dignitaries were forced onto their knees by King Charles, dressed in white tabards with nooses around their neck (Figure 15) [145]. 


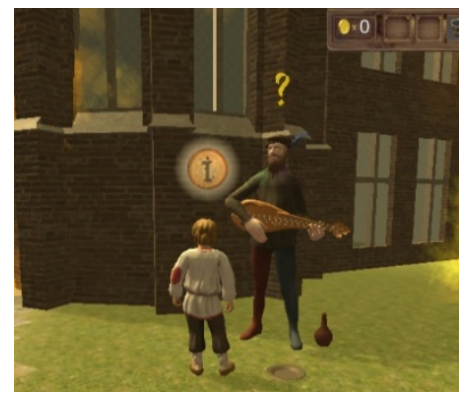

(a)

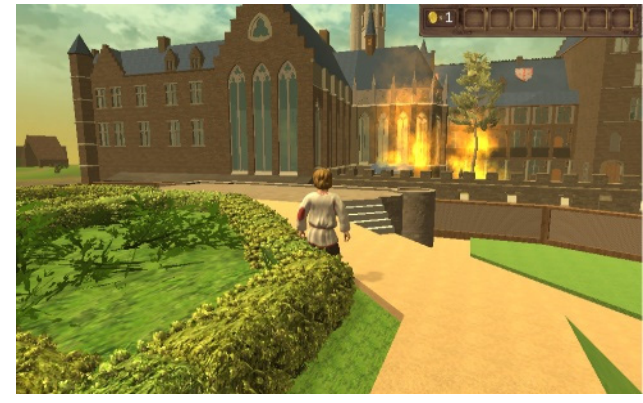

(b)

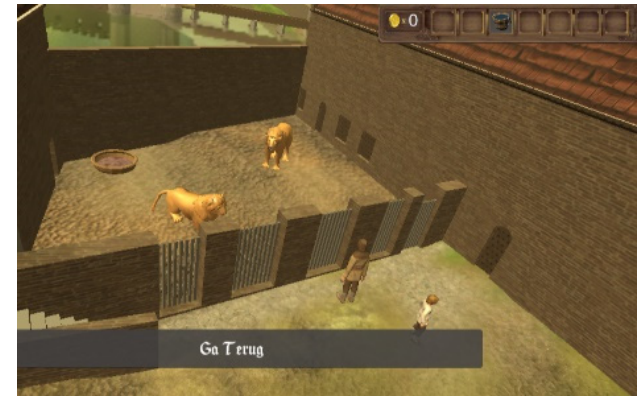

(c)

Figure 14. The animation: (a) A playing musician; (b) A fire demolished part of the castle; (c) The lions, as in the 16th century.

An interdisciplinary animated project, produced for free in co-creation, could start the Animated Spatial Time Machine (AniSTMa). The "server architecture" applied to publish is described in Section 3.7. The viewer contains the present situation in a LOD2 dataset (Figure 16a) and the reconstructed castle. As a result of Terraexplorer for Web (TE4Web), a URL commences the 3D viewer. A time slider demonstrates the nonanimated environment of the castle (Figure 16b). An animated Web Build of $450 \mathrm{Mb}$ is saved in another folder. The integration of the Unity Web build in Terraexplorer is the last step to realise the 4D viewer. By pressing a blue-coloured pin, a website (with castle information) opens in a popup menu (Figure 17a). By pressing a red-coloured pin, a link to the animated 3D Web build will be activated (Figure 17b). Streaming on WIFI takes about two minutes before starting the scene. In the future, optimisation will be needed to reduce the number of polygons without ignoring quality optimisation. One could effortlessly use the controllers, because this gamification (with a historical and educational function) has been made for everyone. The mouse and a few arrows on the keyboard constitute the only tools. Using the " $\mathrm{I}$ " button, a dialogue opens when encountering a question mark. By integrating the Unity and Skyline software, the AniSTMa concept becomes possible.

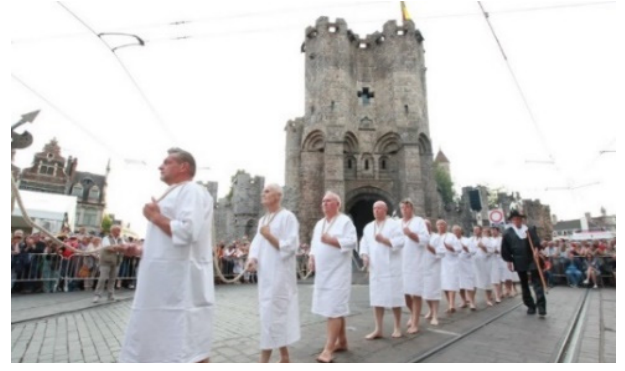

(a)

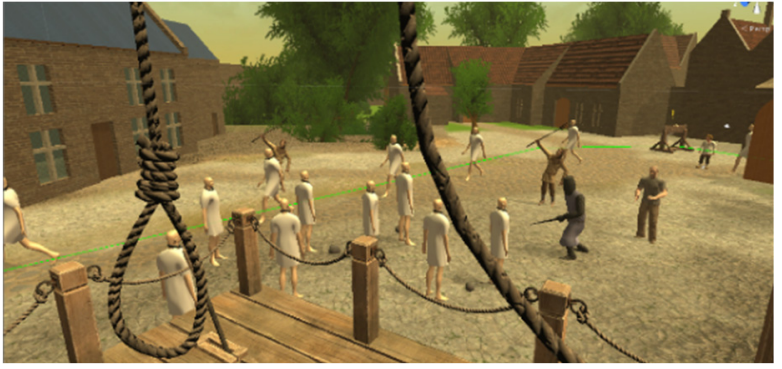

(b)

Figure 15. The noose barriers: (a) The yearly physical walk in Ghent; (b) The virtual Princes' Court Castle.

The Transmedia Storytelling (TS) in this project builds on Ghent's three-year “3D city game Ghent" adventure. This co-creative project has been promoted during several events and was broadcast on local television. During Flanders' most significant "ICT for government" event ("Meeting Day Information Flanders" with 3000 participants) at the International Congress Centre Ghent, the 3D Team of Ghent city organised a whole track regarding "The parallel virtual universe in Ghent" on 26 November 2019. The co-creative participants played a performance; someone in King Charles's outfit met someone else as Gerard Mercator (born in the Ghent surroundings in 1512, inventor of the world's first atlas) and performed a historical dialogue on scene (Figure 18a,b). A co-creative citizen also established a website on the digital castle and promoted guided walks (Figure 18c) with a large rolled-up aerial photo with 3D printed buildings of his work [146]. 


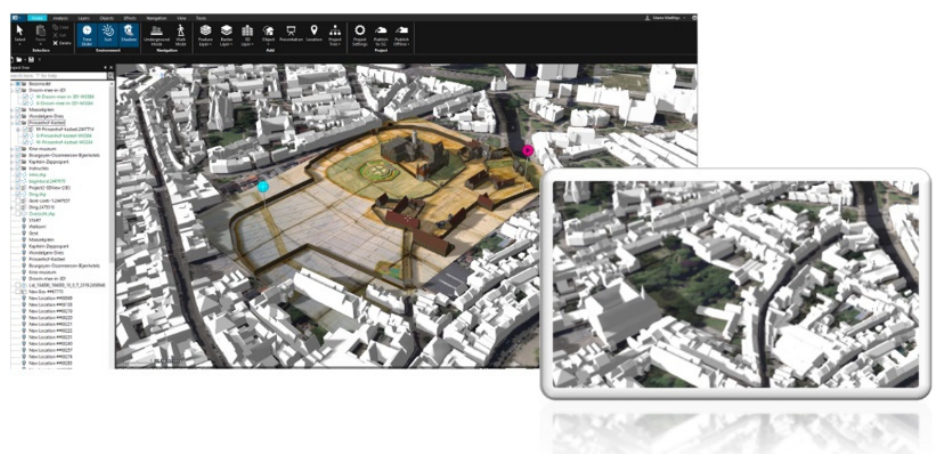

(a)

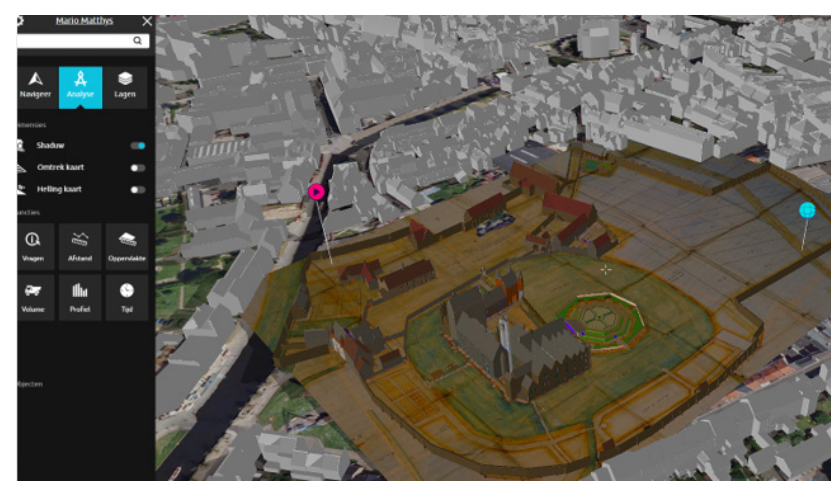

(b)

Figure 16. The virtual castle online: (a) Integrated into Ghent's 3D model (2009), in TerraExplorer (not for public use); (b) TE4Web, a 4D web application online, the old castle in the 16th century surrounded by the 3D model of Ghent in 2009.

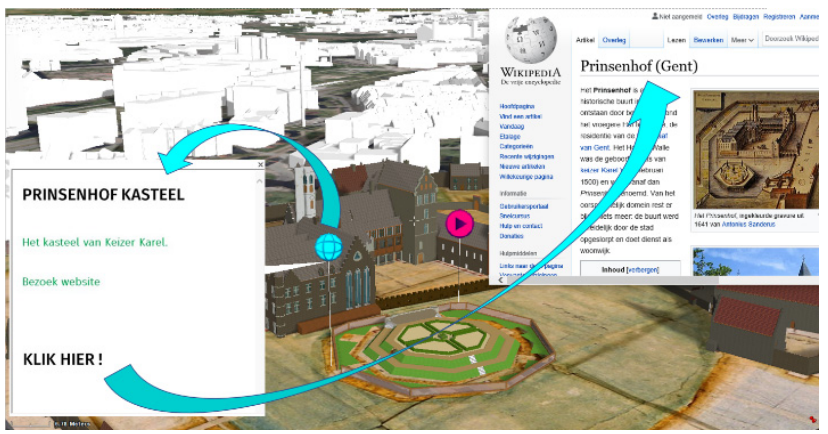

(a)

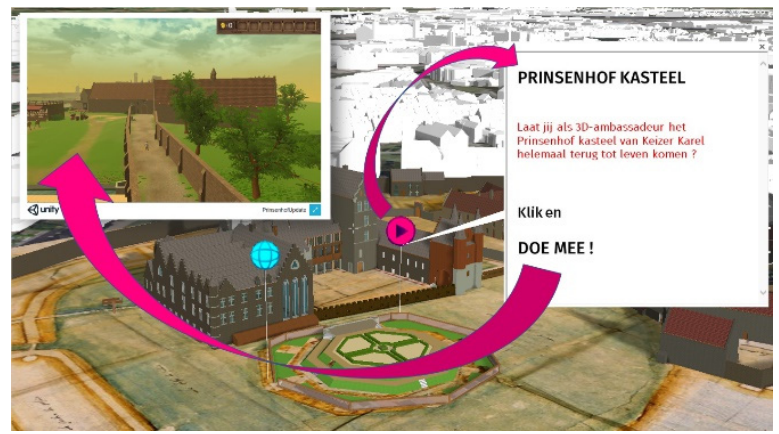

(b)

Figure 17. TE4Web: (a) Link to the website; (b) Link to the Unity WebGL Build.

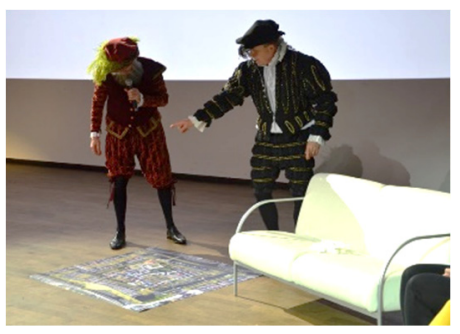

(a)

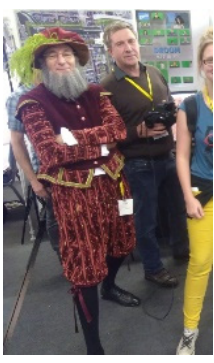

(b)

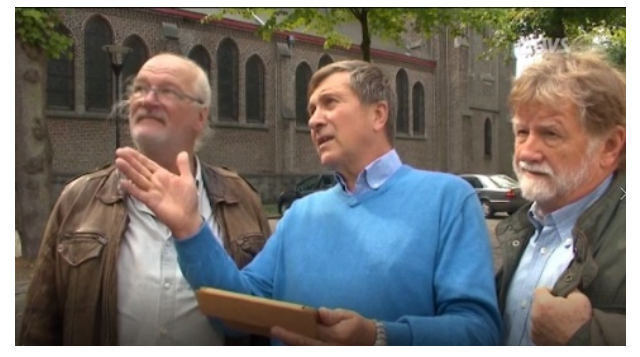

(c)

Figure 18. Co-creative citizens: (a) A historical outfit on scene, Meeting Day Information Flanders, 28 November 2019; (b) Historical outfit likewise; (c) Guided walk by citizens (telling about the 3D modelling).

Transmedia Storytelling (TS) goes further, because the project also triggers other possibilities. In the real Princes' Court Castle neighbourhood, a bronze scale model was stolen during 2011 (Figure 19c), and a replica made of synthetic resin was also demolished due to vandalism (Figure 19d) [147]. In 2020, one investigated whether or not the digital co-creative 3D model could be printed cheaply in 3D. These maquettes were preceded by an old, big, wooden scale model of the whole city centre in the 16th century, made before the 1960s and a golden piece for tourists in Ghent Belfry, which was also part of the Princes' Court Castle in a little corner (Figure 19a,b) [148]. This maquette has been scanned in 3D and will be incorporated into the Animated Spatial Time Machine (AniSTMa). 


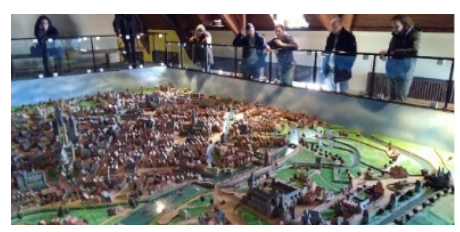

(a)

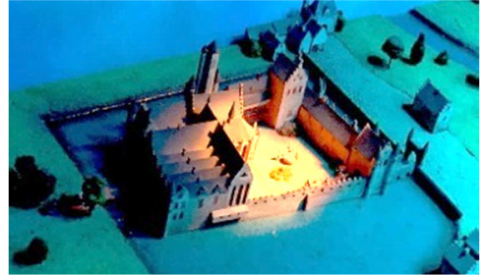

(b)

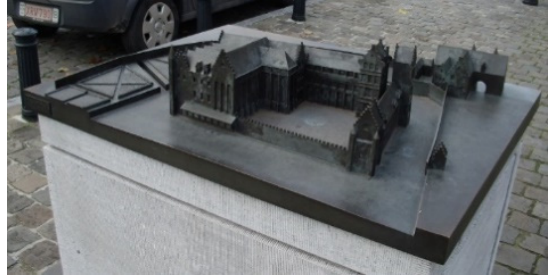

(c)

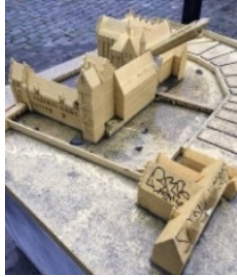

(d)

Figure 19. Maquettes: (a) Ghent 16th century, Kina Museum; (b) Princes' Court detail; (c) Bronze scale model of the Princes' Court, 1999 open-air (stolen in 2011); (d) Synthetic resin, 2015 (damaged by vandalism), on the Princes' Court square, copyright: City of Ghent [149].

The co-creative team will continue to work on this 3D model, adding more gameplay and scenes (Figure 20a). Conversations are ongoing with the Department of Educational Sciences of Ghent University to collaborate on the integration of co-creative projects in education regarding Ghent's history and geography. The online sessions are continued repetitively; new physical workshops will take place after the COVID-19 crisis (Figure 20b).

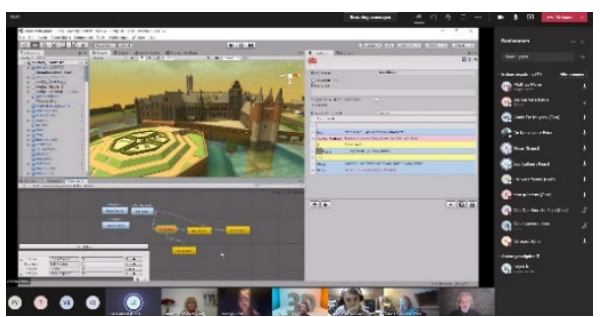

(a)

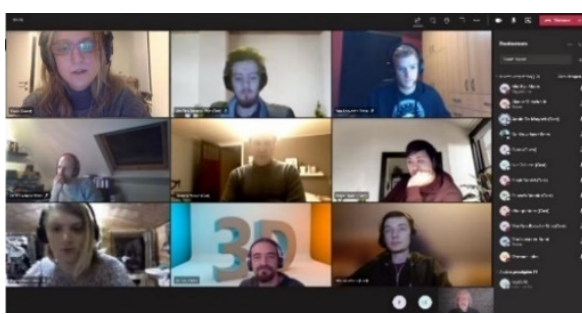

(b)

Figure 20. Online meeting 16 February 2021: (a) Online discussion using Unity; (b) Webinar.

\subsubsection{Dries Wondelgem}

The inhabitants' focus was also on Ghent's suburbia. The Saint Catharina Church environment (Dries in Wondelgem) became a subproject by a resident, Peter De Keukelaere. Being a professional System Engineer Programmer, he developed as a hobbyist 3D modeller in the 3D Studio Max and Blender. He started modelling the Saint Catharina Church (in the middle of a graveyard surrounded by trees) (Figure 21a). Besides modelling, he wrote code in C\#, integrating his model in Unity. The idea grew to invent something regarding the church's architecture in gamification (Figure 21b,c). Using the city's open 3D data as primary data, he modelled the details based on pictures (without 3D scanning). After completing the 3D modelling of the existing church, he removed some architectural details as if it was demolished in reality. In Unity, users had to find the missing architectural details in the game. The choice was to promote a complete digital version of the architectural knowledge game online, knowing that board games (combined with RFID technology) are still very attractive to many (playing) children and young people [150]. 


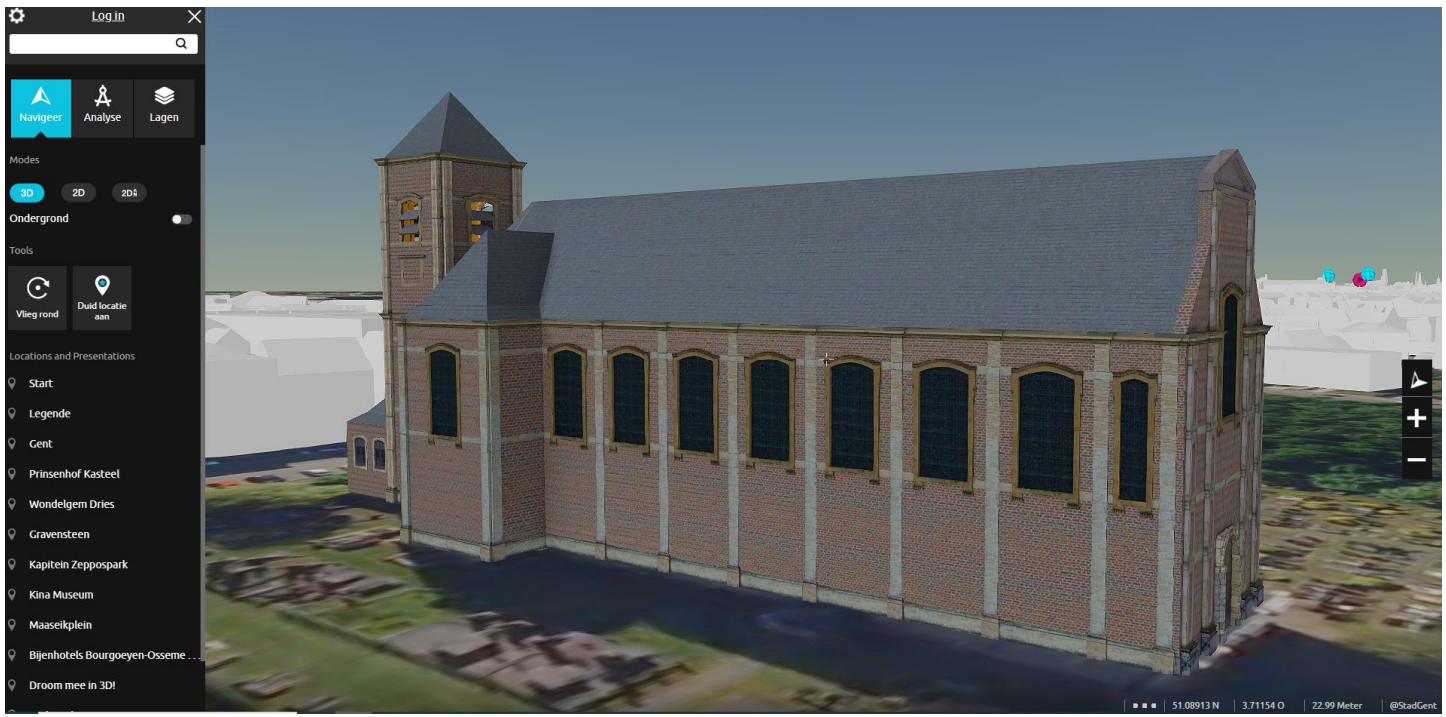

(a)

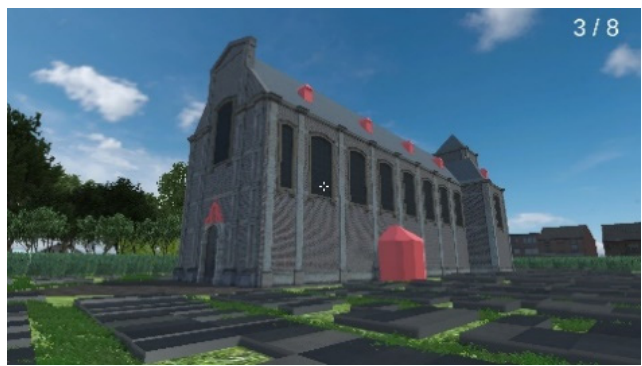

(b)

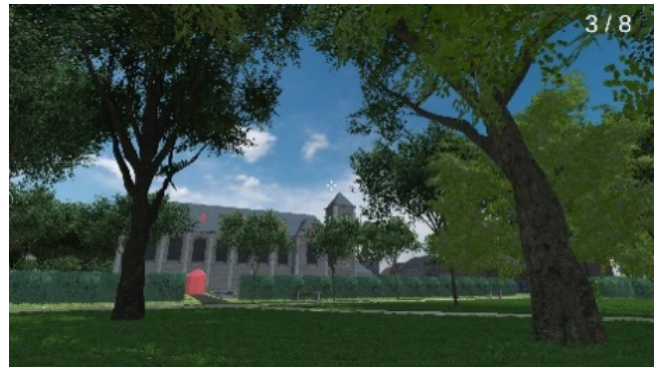

(c)

Figure 21. Three-dimensional model of the Saint Catharina Church: (a) The basic model; (b) The architectural game; (c) The environment.

It is remarkable that this 3D model, which started as a co-creative project on cultural heritage, was strong enough to be applied in postdoc research on cycling satisfaction by the Faculty of Medicine and Health Sciences of Ghent University [102]. The modelled green infrastructure, longitudinal textured architecture and street details were immediately deployable. As a result, the 3D project became available in VR while using the HTC-Vive glasses (Figure 22a) and in the Ghentian 3D C.A.V.E (Figure 22b). The construction of the bike simulator was performed by employing a bike on rollers. This project illustrates a kind of TS with a multifunctional use of 3D data (Figure 22c).

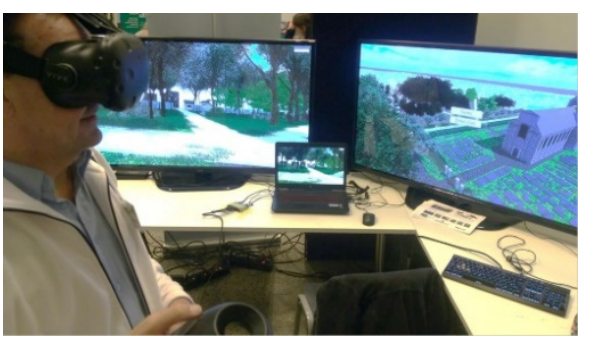

(a)

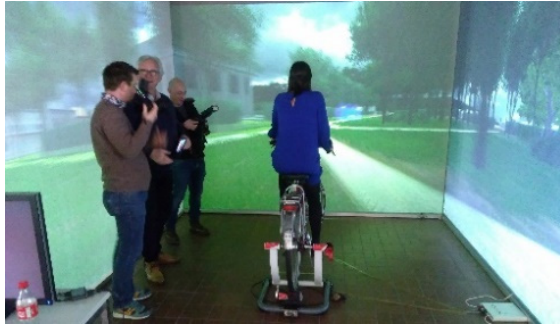

(b)

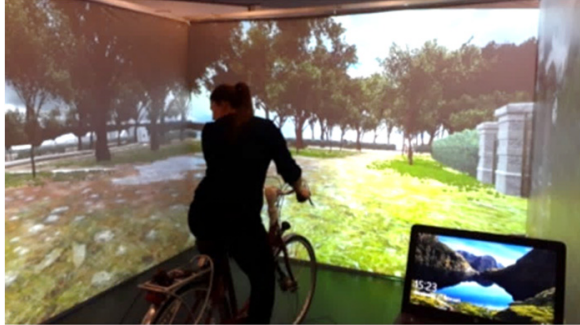

(c)

Figure 22. The architectural game: (a) While using the VR glasses; (b) In a 3D C.A.V.E.; (c) The bike simulator. 


\subsubsection{The Old Spanish Castle}

The old Spanish castle is another 16th century settlement in Saint Macharius near the city centre, located at the confluence of the rivers Scheldt and Lys, where Ghent arose. This project is a combination of different 3D models. One part is a reconstruction of the old Spanish Castle produced in a co-creation (Figure 23a). However, a previous 3D model was a reconstruction of the historic church Saint Bavo's Abbey in Ghent (made by professionals in 2010, funded by the European Shaping 24) (Figure 23b) [151]. As a third part, the 3D Team trainees started to collaborate with the co-creative group, aiming to reconstruct the old beast market and slaughterhouse (20th century) at the same location (Figure 23c). After integrating these various architectural reconstructions, they augmented the historical aspects of the reconstructed 3D environment with UFOs from the future in order to realise a time voyage (Figure 23d). Through these UFOs (controlled by the player), you can visit the virtual environment from the 21st century, saving cows back in time sold on this market during the 20th century (if not, which would end up in the slaughterhouse on the same location), using a virtual gripper arm such as from a Luna park, coming out of the UFO. It is a spectacular application in the AniSTMa, bringing history, present and future together in one project by means of time portals, referring to the film "Back to the Future" [152]. The integration of several 3D models of the same geographic location in various periods (made by different authors) causes digital challenges in connecting these different datasets of varying periods. Another type of Transmedia Storytelling (TS) is evident from the fact that the City of Ghent, involved in the European Sustainable Development Goals (SDG), showed interest in utilizing this game to promote the European goal to "eat less meat" [153]. During a conference, the "save the cow" game demonstrated the manner in which 3D game engines might encourage interactive communication.

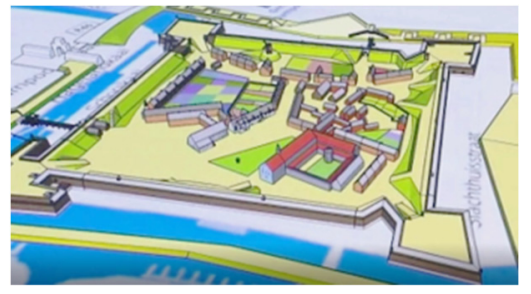

(a)

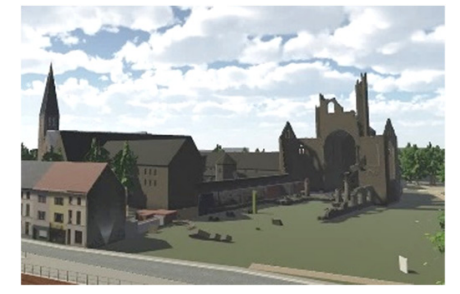

(b)

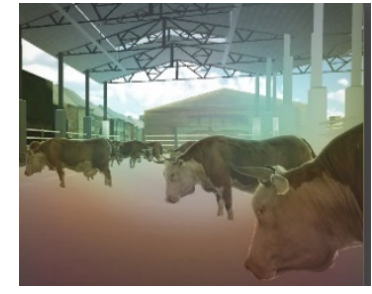

(c)

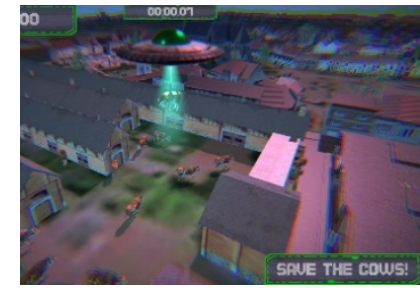

(d)

Figure 23. Three-dimensional model of the Spanish Castle: (a) The demolished castle (D. Van Wittenberghe); (b) The ruin of an old church (Shaping 24 project 2008); (c) Cows at the old beast market; (d) Game "save the cow", time voyage with UFO.

\subsubsection{Ghent Centre (13th Century) and the Castle of the Counts}

One of the co-creative group's first projects included the production of a detailed 3D model of the unique (more than 1000 years old) Castle of the Counts in the City Centre, starting from the LOD2 models and 3D scans. The idea was to play with a Ghentian Drake in and around the castle (Figure 24a,b), combining an exact copy of the actual situation and fantasy in a historical context. The co-creatives built some little games in the courtyard and the castle's interior (Figure 24c). Even a statue of the former historical figure "Jacob Van Artevelde" was scanned in 3D and animated in 3D gamification (Figure 24d). 


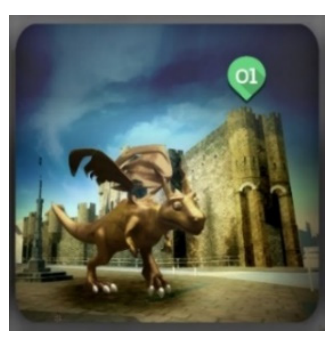

(a)

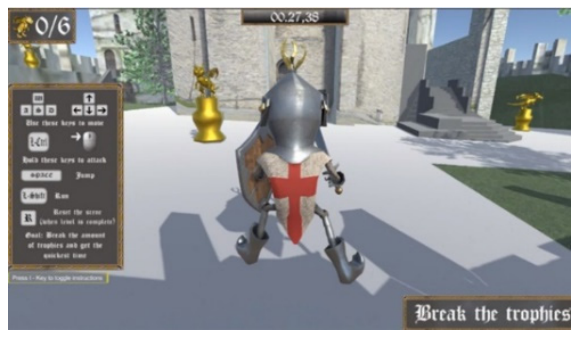

(b)

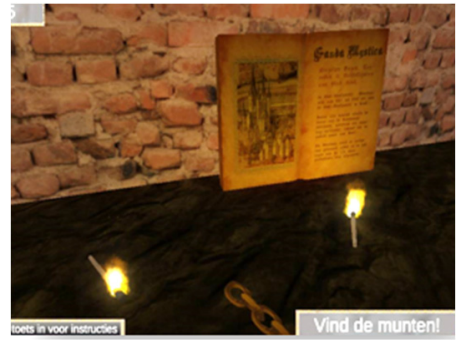

(c)

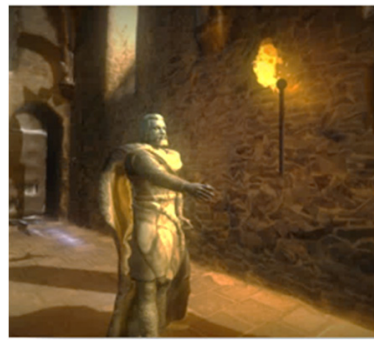

(d)

Figure 24. Castle of the Counts: (a) Ghentian Drake; (b) The game; (c) The dungeon; (d) A "Jacob Van Artevelde" dialogue.

Later on, the scene was expanded to the city centre, reconstructing the 13th century by trainees of the 3D Team based on the archaeological research drawings (Figure 25a). In medieval times, an old graveyard and building blocks surrounded the Saint Nicolas Church in a combination with wooden and stone houses (Figure 25b). The trainees studied the architectural typology in collaboration with the city administration's archaeology experts and monument caretakers. In this case, the 3D Team professionals (and trainees) more specifically continued to work on the citizens' co-creative impulses in and around the castle. In this project, the co-creative spirit also persisted in the trainees' group, because the trainees in game development programming cooperated with the 3D modellers and media, film and architecture students in view of new scenes (Figure 26).

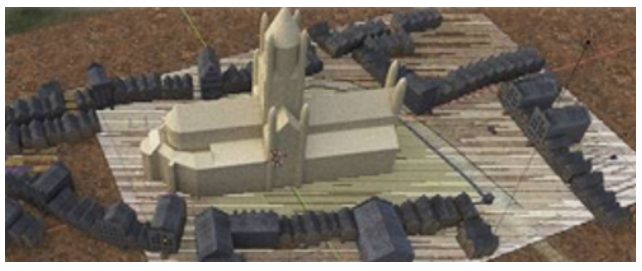

(a)

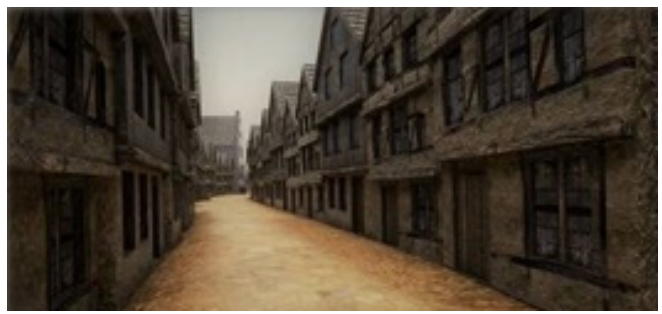

(b)

Figure 25. Medieval Ghent Centre (the making of), 2018-2019: (a) An overview; (b) The 13th century architectural typology.

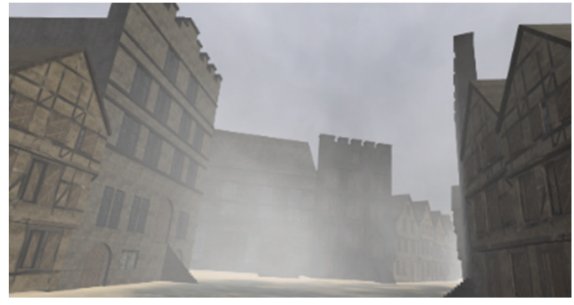

(a)

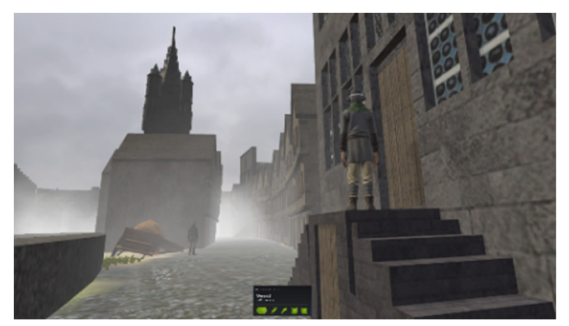

(b)

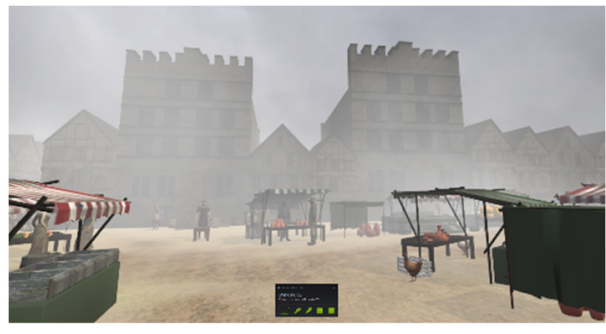

(c)

Figure 26. Medieval Ghent in VR: (a) Goudenleeuwplein; (b) Sint Niklaasstraat; (c) Korenmarkt.

The results were demonstrated during the "Archaeological Days" on 15 June 2019 (Figure 27a,b). An HTC-Vive VR environment showed a Unity build, also used in AR by means of a Hololens. The archaeology experts and dozens of visitors were excited about the co-creative project's results, also promoted during other sessions (Figure 27c). 


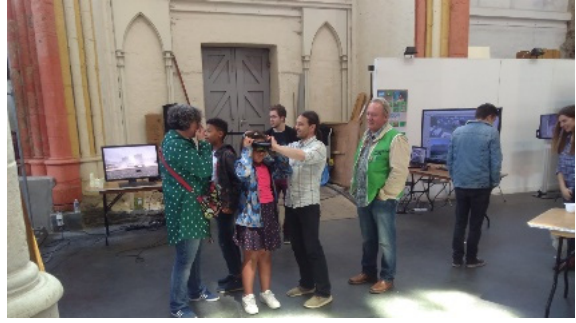

(a)

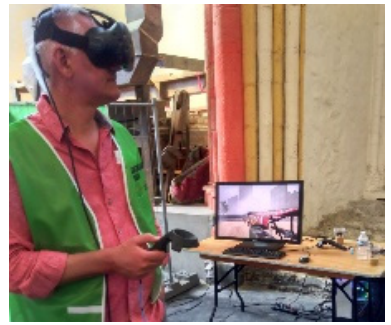

(b)

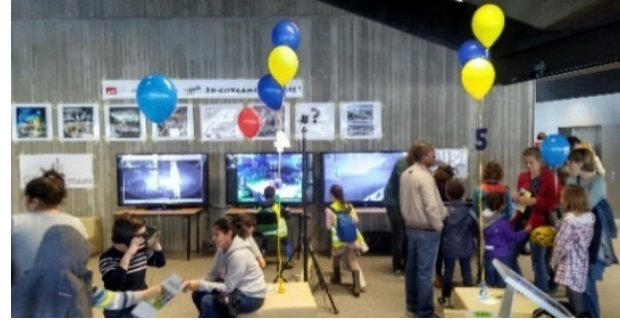

(c)

Figure 27. Archaeology days 15 June 2019, Saint Nicolas Church: (a) VR glasses HTC-Vive Ghent; (b) AR glasses Hololens; (c) A workshop and demo in the city library "De Krook".

\subsubsection{The South Railway Station and the Old Winter Circus}

On 12 March 2017, a new central library, "De Krook”, was inaugurated. A reconstruction of the historical situation, including the indoor winter circus of the 19th century, was done by the 3D Team, based on 3D scans of the still existing interior and archaeology. In addition, the roof, which had been destroyed by a major fire on 12 December 1920, was reconstructed (Figure 28a,b). An animated show imaging elephants at the indoor winter circus was also part of the game (Figure 28c,d). While the 3D Team reconstructed the environment, co-creative residents modelled the old railway station of Ghent South, built as one of the first railway stations in Belgium and Europe in 1837 (two years after the first train on the European mainland from Brussels to Mechelen) (Figure 29a-c). The situation during 2017 was also 3D modelled in more detail by the trainees, starting from the city's LOD2 model (Figure 29d). Several teams collaborated on this project: some in Sketchup, others in sophisticated software. All 3D models were combined into Unity. Unique was the parallel working manner by the different groups on the entire project.

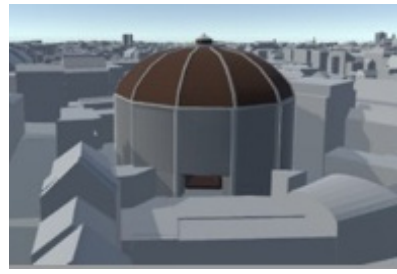

(a)

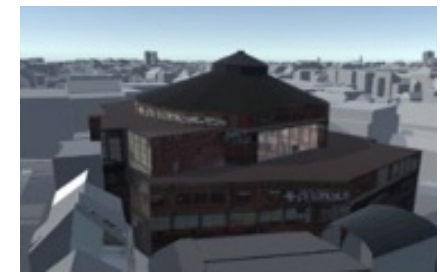

(b)

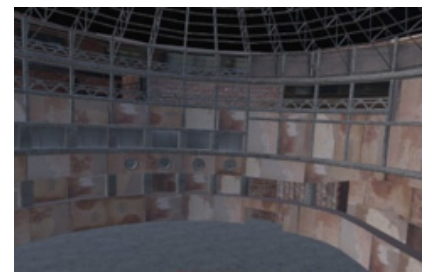

(c)

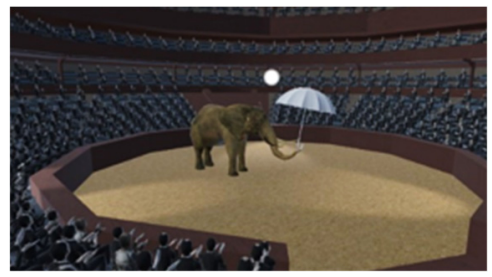

(d)

Figure 28. Winter circus Ghent: (a) The reconstruction of the exterior 1888; (b) The situation in 2018; (c) 3D scan of the existing interior in 2017; (d) The reconstruction of the performance with elephants at the end of the 19th century.

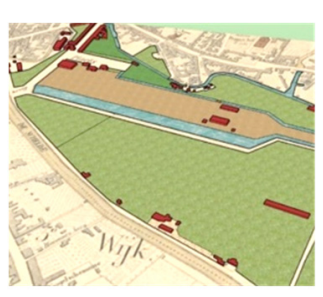

(a)

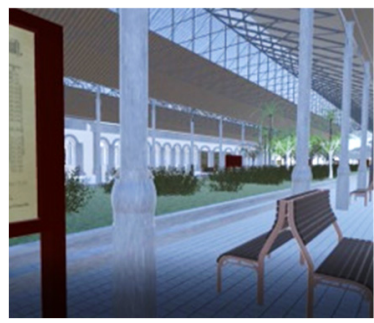

(b)

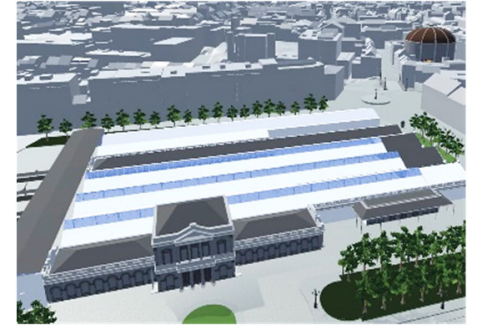

(c)

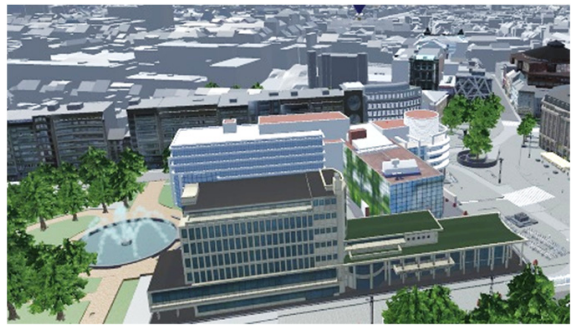

(d)

Figure 29. South railway station: (a) Environment of the first station in 1837; (b) The interior; (c) The situation in 1904 (D.Van Wittenberghe); (d) Same location, the city administration centre in 2017.

\subsection{Process Guidelines}

Several components can be distinguished in the processes described during various phases, emphasizing the generation of 3D data evoking the past. Figure 30 shows the connection of different domains on the intersection of co-creation (in orange), historical 
and open 3D data used in free software (in purple), 3D city model (in blue) and 3D game development (in dark blue), 4D web architecture (in green) and TS (in grey).

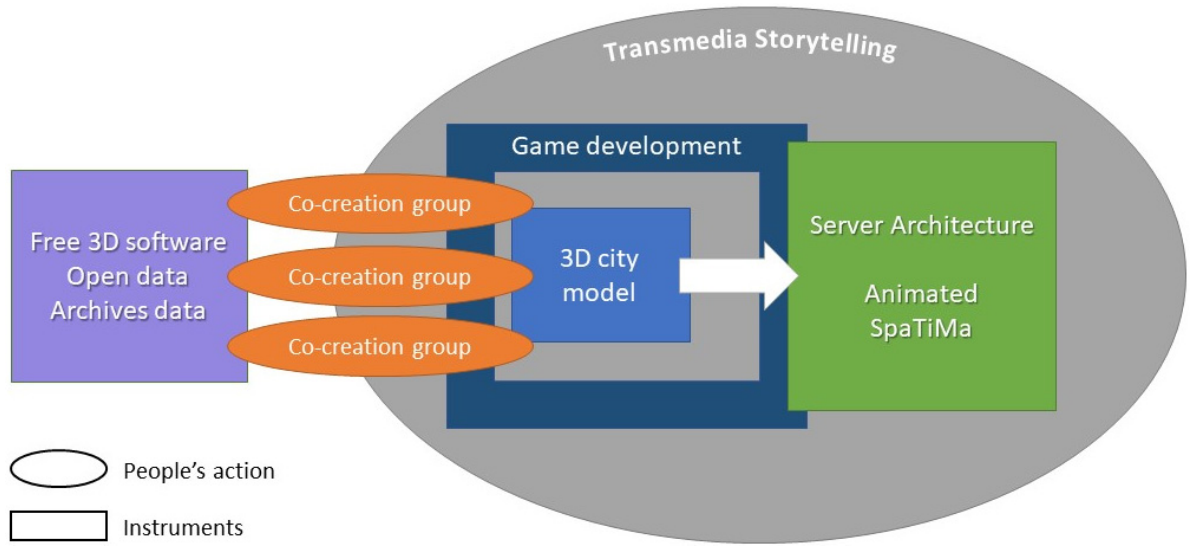

Figure 30. Different components in co-creative 3D modelling for the reconstruction of the past.

This research discusses the manner in which the 3D co-creation can support the reconstruction of cultural heritage. In order to do so, a process description was performed regarding multidisciplinary actions. Three crucial parts could be distinguished in the process flow: the preliminary process, action time and postprocess (Figure 31a), in other words: the recruitment phase, co-creative work and filling up the contents in an Animated Spatial Time Machine (AniSTMa). These process timeline functions are related to several reconstruction periods and might start on a different date (Figure 31b).

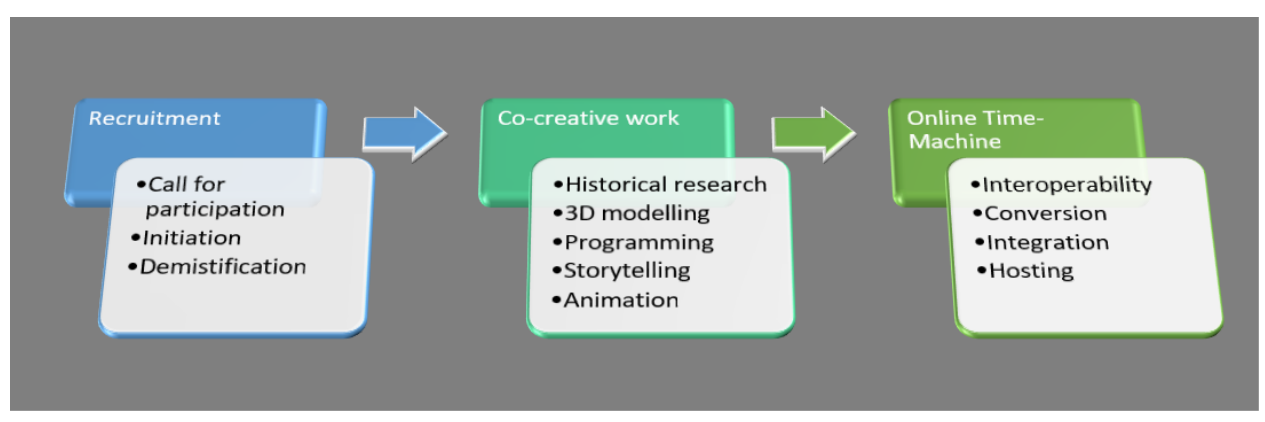

(a)

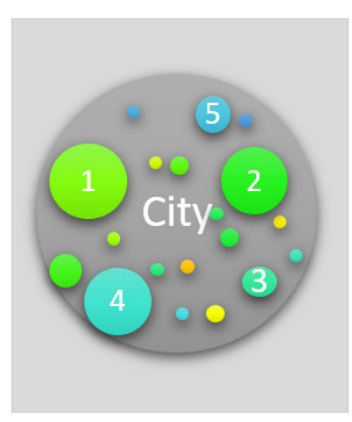

(b)

Figure 31. Process flow: (a) Actions in the process flow; (b) Projects spread over the city with varying start and end times.

The Ghent cases demonstrate that opportunities and lessons have been learned. In order to replicate the process of co-creative 3D modelling, a guideline (checklist) has been presented in order to reconstruct the past. The three crucial parts in a co-creative 3D modelling process embrace different topics that need attention:

1. The recruitment:

- Communication and promotion

2. The co-creative work:
a. Workshops
b. Historical research
c. Open 3D data
d. Software
e. Hardware
f. Logistics
g. Contents and Transmedia Storytelling 
3. The online Animated Spatial Time Machine (AniSTMa):

- $3 \mathrm{D}$ web

The overall coordination could be a collaborative assignment. A helicopter view of the process and various topics in this checklist is necessary (Figure 32). The coordination could also be done by a 3D ambassador appointed by the neighbourhood.

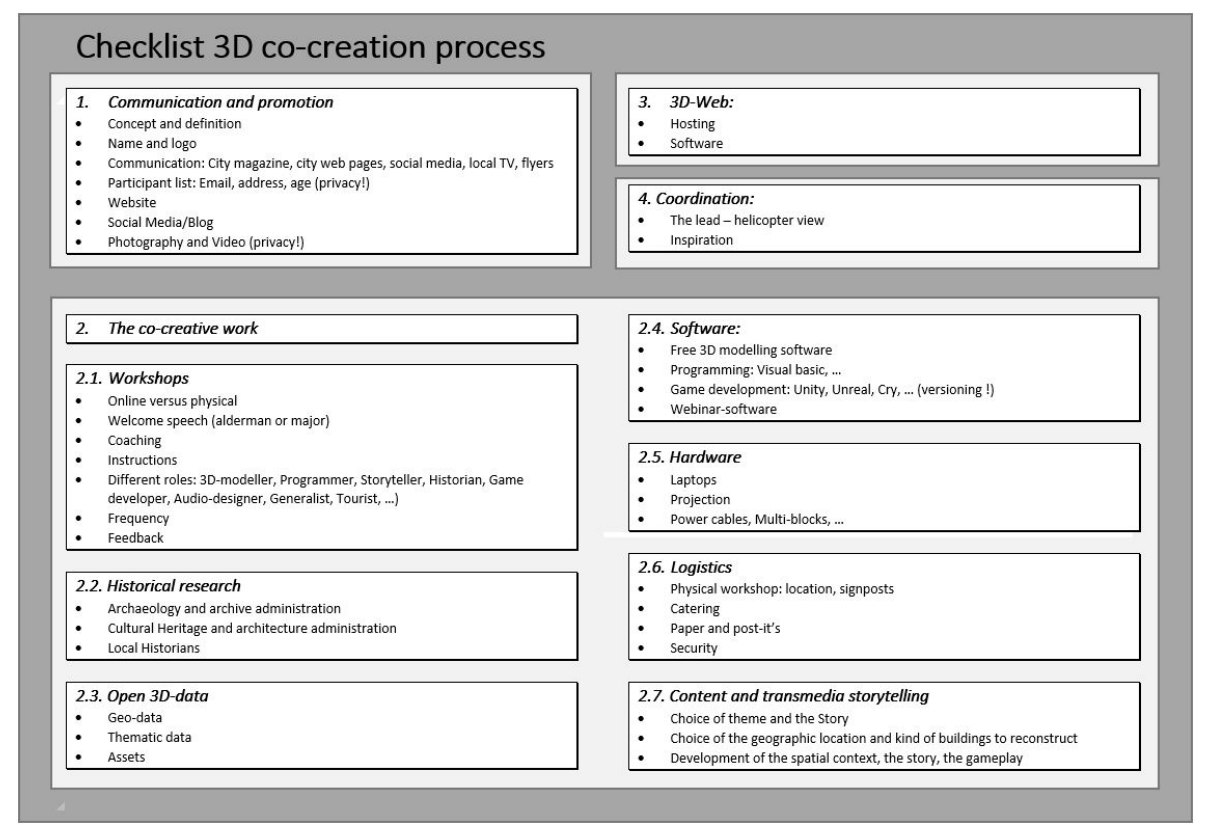

Figure 32. Framework: Checklist for organizing the co-creative 3D modelling process.

\subsection{Space-Time Diagram in Animated 3D City Modelling: The "Bagpipes Model" (BP-M)}

While reconstructing history, the impossibility to measure or scan makes it rarely accurate. The temptation arises to add animation to 3D reconstructions with a higher fantasy, which means a higher uncertainty. Milgram's Reality-Virtuality continuum indicates whether one can look around in reality or VR (or between) (Figure 33a) [25]. Looking to the past by using 3D models is a kind of navigation in Virtual Reality (even when not using the VR glasses) with uncertainty. Daydreaming is also a kind of VR without digital interfaces but with fantasy. In 2002, Stapleton et al. added the parameter "fantasy" to the graph of Milgram to create the imaginary world stories (Figure 33b) [154]. Périnaud argues that the dimension of time should not just be added as an attribute, and Ohori studies 4 D cubes (tesseracts) to integrate time and space $[36,155]$. One should utilise integrated multidimensional models in the ideal world, and these theories can also be applied when updating the 3D city models. Nevertheless, this is not evident for the 3D modelling of the distant past and for disappeared objects. Three-dimensional reconstructions occur worldwide in various small locations and are spread over time outside a GIS context. If this research guideline is widely applied in different cities and neighbourhoods, GIS specialists will not always be available to incorporate these into a 3D city model. Therefore, it is easier to use the time attribute for animated 3D projects of demolished architecture and to use it to arrange these in the 4 th dimension of a 3D city model. 


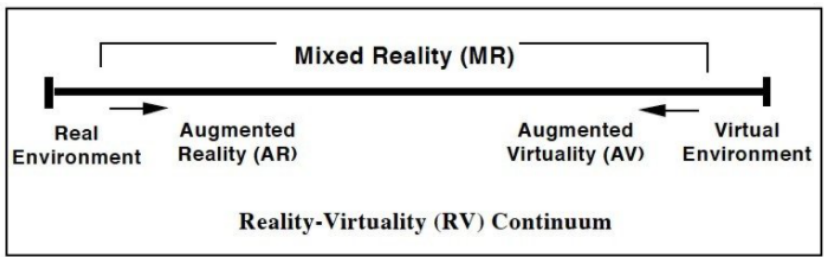

(a)

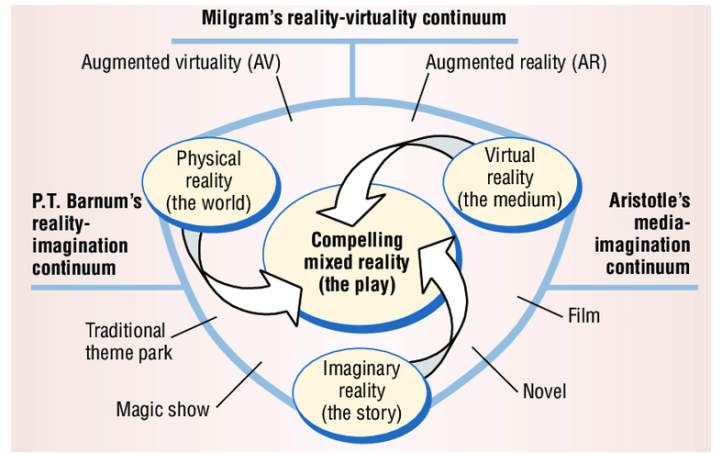

(b)

Figure 33. Reality-Virtuality continuum: (a) Milgram's diagram, 1997 [25]; (b) Mixed fantasy framework, Stapleton [154].

Knowing whether (or not) a 3D model is an exact copy of the reality or an interpretation is essential. For the animations, the degree of fantasy is high. Researchers from various disciplines looked for the best way to visualise the relation between space and time activities (Figure 34a,b). The space-time paths were inserted in various 3D schemes. The economist Joseph Pine II illustrated the relation between space, time and matter in a scheme (Figure 34c), showing the balance between the real and virtual world.

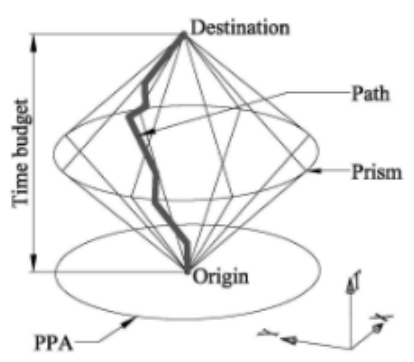

(a)

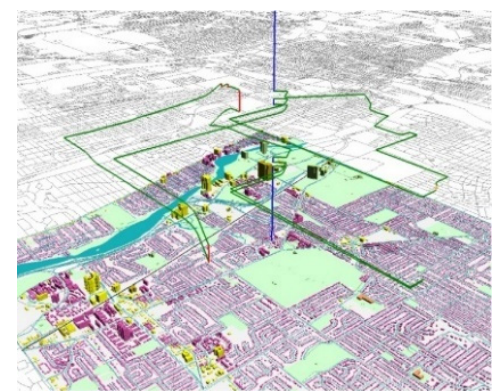

(b)

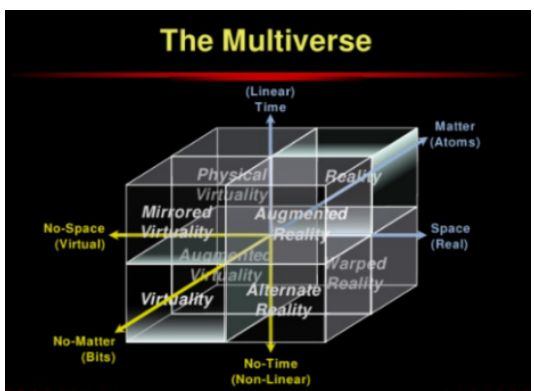

(c)

Figure 34. (a) Space-time path and prism [156]; (b) Space-time path, Kwan [157]; (c) Multiverse, Joseph Pine II [158].

The availability of 3D models on the past, including the model's accuracy, is conceptually visualised in Figure 35. Beneath a transparent $X Y$ plane (the present), a box represents history. Several random polygons indicate the possible availability of 3D models. A red colour indicates the physical situation of a neighbourhood in the past (lower in the box) or today (on the transparent XY plane). Because it is never completely obvious how long a physical state lasted (in the past), a polygon's height indicates a possible period of existence. Other colours show whether (or not) a 3D model has been made for a particular geographic entity: an exact copy of the physical reality (green), uncertain (yellow) or pure fantasy (blue). The bottom plane of a (green, yellow, blue) polygon indicates when a 3D model was created, and the top plane illustrates if the 3D reconstruction of the underlying red period is available today. Usually, there is some time between the object's demolition and the creation of a 3D model, indicated by the black vertical lines. 

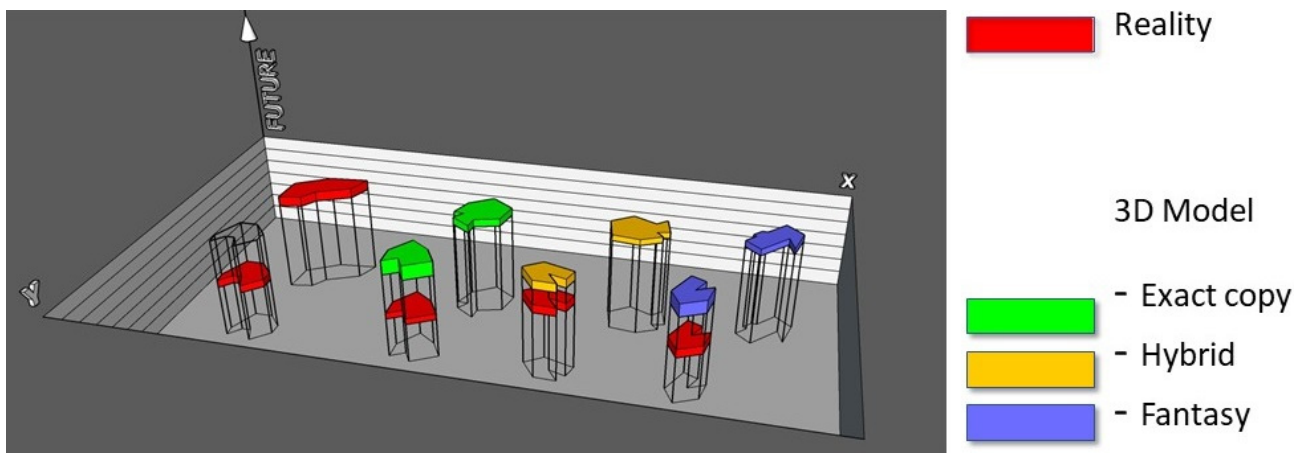

Figure 35. Space-time continuum: physical reality versus virtual reality, hybrid and fantasy.

Ideally, we do not indicate 3D reconstructions of larger areas using polygons, but we consider a degree of inaccuracy for each point on Earth regarding various periods. A conceptual scheme, the "Bagpipes Model" (BP-M) (Figure 36), tries to visualise this. A red bone represents the exponential time range for any point on the Earth's surface, starting with the purple marble as the earth's beginning time. The outer transparent sphere illustrates the present, constantly expanding. The closer to the start of the earth, the shorter a time unit, the closer to the present, the longer a time unit. Each intersection of a red bone with the transparent membrane of the present shows a moment of the physical shape of a point on Earth at that time. A second cylinder (around the red bone) means that a 3D model is available for that point; the length illustrates the period that the 3D model represents. As in Figure 34, the green colour shows an exact copy, orange shows uncertainty, and dark blue represents fantasy. A white third cylinder surrounding the second means the animation already exists. If no 3D model is present, the points remain red. This conceptual Bagpipes Model (BP-M) might inspire data structures to integrate the animated 3D models and events in a geographical 3D city model (as a part of TS).

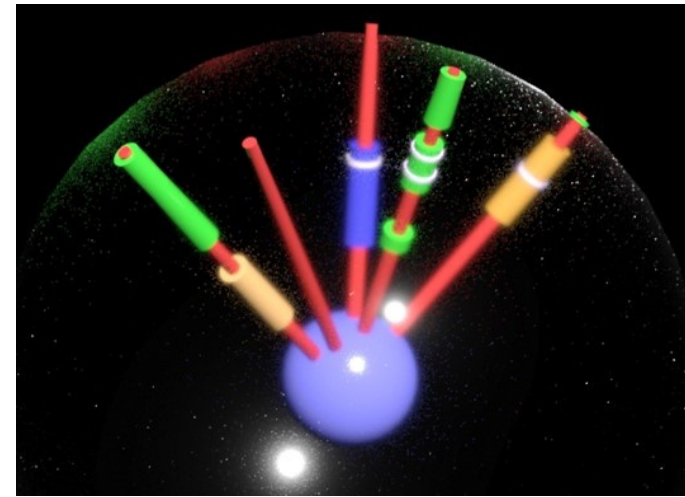

Outer shell: the present

Red bone: real world

Green bone: 3D model exact

Orange bones: 3D model uncertain

Blue bones: 3D model fantasy

White bones: an animated model

Blue marble: start of earth

Figure 36. Space-time 3D reconstruction for each point on earth, the "Bagpipes model" (BP-M).

\section{Results and Discussion}

Building an online 4D Animated Spatial Time Machine (AniSTMa) is no longer a hardand software problem, even though we still need to combine different software programs for spatial analyses, 3D models and animations. To stream 4D online, commercial solutions exist for basic applications without writing a new code. This research did not focus on the digital problems' data structure or interoperability questions but on the manner in which the 3D data of the past should be generated. Could the 3D reconstruction of the lost architecture and environments be improved by promoting 3D co-creation? Based on Ghent's cases, a process description was performed on multidisciplinary actions at the intersection of different domains using 3D co-creation: historical and open 3D data, softand hardware, 4D web architecture, 3D gamification and TS. A roadmap for 3D co-creation was not available before the start and the process was built on voluntariness without 
deadlines. Some subprojects ended without results because of the participants' drop-out or lack of time among officials for a nonpriority task. The physical workshops intended to stimulate the discussion and social contact between the participants (Figure 37). Webinars could occur more frequently, which the pandemic triggered. The use of the output interfaces as VR/AR technology and 3D printing could only be realised by physical interaction.

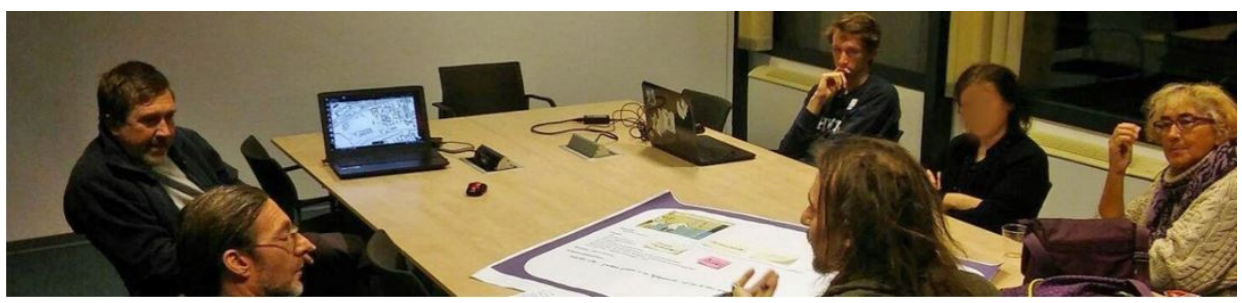

Figure 37. Co-creative brainstorm on Transmedia Storytelling and gameplay (2017).

It was nice to see that Transmedia Storytelling (TS) often seemed a stimulating environment for participants to stay in co-creation. Nonspecialists could, an hour after drawing their first 3D models, experience this drawing in VR glasses. Combined with the integrated animated characters of another co-creator, new gameplay was conceived. This inspired others to enter a physical room in the outfit of a historical character and the musician began to produce mediaeval music. Transmedia Storytelling affected the participants. As a result of this investigation, a guideline and framework have been developed to multiply the $3 \mathrm{D}$ co-creation concept, reconstructing the past. Furthermore, this co-creative 3D project description inspired the start of a new community for 3D ambassadors in cities concerning "Making an Animated Spatial Time Machine (AniSTMa) by citizens". All projects worldwide could be connected via www.space-times.org (accessed on 2 May 2021) (including the Ghent project). Further research will focus on the availability of the time machine for co-creative projects on future spatial developments.

In 2018, Ramaswamy et al. launched a co-creation framework (CCF) in which he promoted the dynamics of co-creation in an increasingly digitalised world [71]. The framework of co-creation in Ghent grew spontaneous. Everyone has graduated from the kindergarten and has a drawing diploma. Everybody, young or old, can draw before writing. So, 3D drawing starts in free software quickly, more easily than people suppose. The free tutorials and assistance by people who have already gained some experience are sufficient for this kind of 3D modelling. Helping to reconstruct their hometown or district's history and facilitating its interactive communication and gamification about it might become a fascinating hobby. The idea to appoint 3D ambassadors in different neighbourhoods might create a global co-creative 3D community. The success factors of a co-creative project include inspiration and enthusiasm. The 3D co-creative e-participation makes sense. If the municipalities' administration is not authorised, a school, community of retired people, folklore society, schools or youth movement organisations could take the lead.

Hosting a 4D Animated Spatial Time Machine (AniSTMa) should be coordinated on a higher level. A city could establish the hosting, and a region or country might facilitate. In a municipality, it is not easy to indicate who should take the lead. In cities, historians and archaeologists might participate because of their knowledge of the past, geo-ICT experts for the open 3D data, communication specialists for the communication process, ICT specialists for the hosting and co-creative experts to enable the workshops. One suggests setting up a national community in order to connect the groups to fill in the AniSTMa contents. A conceptual space-time diagram, helping to manage the cultural heritage reconstruction (in an AniSTMa), is presented: The "Bagpipes Model" (BP-M). New research is needed in order to translate this model into a new data structure. CAD, BIM, GIS and Game Engines have to be incorporated into one overarching environment to promote dynamic $3 \mathrm{D}$ animations in the long term. The data interoperability of the 3D models has to be 
optimised. In addition, AI and ML should be applied to support the reconstruction. The (semi-)automatic reconstruction handling that started from only one picture is already possible. DL might probably help in the future, and the question is, when AI will have equal interpretive skills to transform the historical sources into 3D city models?

More and more 3D animations will integrate into 3D and 4D web GIS applications. The fusion of the 3D game engines and GIS environments proves to be a challenge. The link between the 3D models and a smell database of historical smells, visualised by the odour wheels, is in prospect. The scent is a part of cultural heritage, but our knowledge of history is still odourless [159]. For Europe, the Odeuropa consortium will spend 2,8 million euros from the Horizon 2020 program on research concerning the "Encyclopaedia of Smell Heritage" [160]. Smell systems (or computers) exist, so combining the 3D reconstruction, $4 \mathrm{D}$ animation, historical sound and music could be completed by adding smells.

\section{Conclusions}

Ghent's cases have learned how co-creative 3D modelling could aid reconstructing the past. The combination of free 3D software, historical research, game development and municipality server infrastructure might offer the components to create an Animated Spatial Time Machine (AniSTMa). The crowdsourcing by e-participation delivers the power to manually reconstruct in $3 \mathrm{D}$ by following the presented guideline a. The collaboration between the citizens, city officers, ICT city partners and trainees shows excellent results. Three-dimensional co-creation offers a new hobby for thousands of people, even without professional experience in 3D or writing code. The historians' participation from the city archive (or folklore society) provides information on the lost architecture and helps to evaluate the reconstructions. More cities might have this inspiration, building on Ghent's examples to bring history alive using the Transmedia Storytelling (TS). If cities do not have the financial resources to reconstruct history, $3 \mathrm{D}$ co-creation will offer a solution. The case of Ghent shows that not only inspiration and knowledge on 3D co-creation but also the free availability of 3D architectural parts of buildings and street furniture of earlier periods could be transferrable. Code and animated historical objects could be open source. An Animated Spatial Time Machine (AniSTMa) could be filled with 3D co-creative projects worldwide. The conceptual space-time diagram, the "Bagpipes Model" (BP-M), should be translated into a data structure in order to collect the historically animated reconstructions.

Author Contributions: Conceptualisation, Methodology, Validation, Formal Analysis, Investigation, Writing-Original Draft Preparation, Visualisation, Mario Matthys; Resources, Data Curation, Mario Matthys and John Vermaut; Writing-Review \& Editing, Mario Matthys, Laure De Cock, Nico Van de Weghe and Philippe De Maeyer; Supervision, Nico Van de Weghe and Philippe De Maeyer; Project Administration, Mario Matthys. All authors have read and agreed to the published version of the manuscript.

Funding: This research was funded by "Research Foundation-Flanders FWO", with a "special PhD Fellowship", grant number 1901421N.

Institutional Review Board Statement: Not applicable.

Informed Consent Statement: Not applicable.

Acknowledgments: The authors would like to express their gratitude to the City of Ghent for collaborating in this research. They would also like to thank Sabine Cnudde for the English support, Francis Vanden Bulcke for the server support and Dirk Van Wittenberghe, Peter De Keukelaere, Annie De Muynck, Luc Callaert, Jo Luycx, Floor Loos, Thomas Vanhuffel and John Vermaut for their participation in the co-creative process.

Conflicts of Interest: The authors declare no conflict of interest.

\section{References}

1. Allegory of the Cave. Available online: https://en.wikipedia.org/wiki/Allegory_of_the_cave (accessed on 15 February 2021).

2. Abbott, E. Flatland: A Romance of Many Dimensions; Basis Blackwell: Oxford, UK, 1884. 
3. Queen Bohemian Rhapsody 1975. A song. Available online: https://www.youtube.com/watch?v=fJ9rUzIMcZQ (accessed on 5 January 2021).

4. Kaku, M. In the eleventh dimension. NewScientist 1997, 153, 32-36.

5. Biljecki, F.; Stoter, J.; Ledoux, H.; Zlatanova, S.; Çöltekin, A. Applications of 3D city models: State of the art review. ISPRS Int. J. Geo-Inf. 2015, 4, 2842-2889. [CrossRef]

6. Kedzierski, M.; Fryskowska, A. Methods of laser scanning point clouds integration in precise 3D building modelling. Meas. J. Int. Meas. Confed. 2015, 74, 221-232. [CrossRef]

7. Buyukdemircioglu, M.; Kocaman, S.; Isikdag, U. Semi-automatic 3D city model generation from large-format aerial images. ISPRS Int. J. Geo-Inf. 2018, 7, 339. [CrossRef]

8. Ohori, K.A.; Ledoux, H.; Biljecki, F.; Stoter, J. Modeling a 3D city model and its levels of detail as a true 4D model. ISPRS Int. J. Geo-Inf. 2015, 4, 1055-1075. [CrossRef]

9. Stoter, J.; Ledoux, H.; Meijers, M.; Arroyo Ohori, K. Integrating Scale and Space in 3D City Models. ISPRS Int. Arch. Photogramm. Remote Sens. Spat. Inf. Sci. 2012, XXXVIII-4, 7-10. [CrossRef]

10. Van Oosterom, P.; Stoter, J. 5D data modelling: Full integration of 2D/3D space, time and scale dimensions. In International Conference on Geographic Information Science; Lecture Notes in Computer Science; Springer: Berlin/Heidelberg, Germany, 2010; Volume 6292, pp. 310-324. [CrossRef]

11. Wei, X.; Bonenberg, W.; Zhou, M.; Wang, J.; Wang, X. The case study of BIM in urban planning and design. Adv. Intell. Syst. Comput. 2018, 600, 207-217. [CrossRef]

12. Jupp, J. 4D BIM for Environmental Planning and Management. Procedia Eng. 2017, 180, 190-201. [CrossRef]

13. Fritsch, D.; Klein, M. 3D preservation of buildings-Reconstructing the past. Multimed. Tools Appl. 2018, 77, 9153-9170. [CrossRef]

14. Bernard, Y.; Barreau, J.-B.; Bizien-Jaglin, C.; Quesnel, L.; Langouet, L.; Daire, M.-Y. 3D Digitisation and Reconstruction of a Capital in North-Western Gaul: Interim Results on the City of Alet. In Proceedings of the 8th International Congress on Archaeology Computer Graphics, Cultural Heritage and Innovation, Valencia, Spain, 5-7 September 2016; pp. 438-440.

15. Verstockt, S.; Milleville, K.; Ali, D.; Porras-bernardez, F.; Gartner, G.; Van De Weghe, N. EURECA-EUropean Region Enrichment in City Archives and collections. In Proceedings of the 14th Conference Digital Approaches to Cartographic Heritage, Thessaloniki, Greece, 8-10 May 2019; pp. 1-9.

16. Giordano, A.; Friso, I.; Borin, P.; Monteleone, C.; Panarotto, F. Digital Research and Education in Architectural Heritage; Münster, S., Friedrichs, K., Niebling, F., Seidel-Grzesińska, A., Eds.; Communications in Computer and Information Science; Springer International Publishing: Cham, Switzerland, 2018; Volume 817, ISBN 978-3-319-76991-2.

17. Herold, H.; Hecht, R. 3D Reconstruction of Urban History Based on Old Maps; Springer International Publishing: Cham, Switzerland, 2018; Volume 817, ISBN 9783319769912.

18. Saldaña, M. An integrated approach to the procedural modeling of ancient cities and buildings. Digit. Scholarsh. Humanit. 2015, 30, i148-i163. [CrossRef]

19. Döllner, J. Geospatial Artificial Intelligence: Potentials of Machine Learning for 3D Point Clouds and Geospatial Digital Twins. PFG-J. Photogramm. Remote Sens. Geoinf. Sci. 2020, 88, 15-24. [CrossRef]

20. Pelacho, M.; Ruiz, G.; Sanz, F.; Tarancón, A.; Clemente-Gallardo, J. Analysis of the Evolution and Collaboration Networks of Citizen Science Scientific Publications; Springer International Publishing: Cham, Switzerland, 2020; ISBN 0123456789.

21. Ballatore, A.; McClintock, W.; Goldberg, G.; Kuhn, W. Towards a usability scale for participatory GIS. In International Conference on Geographic Information Science; Lecture Notes in Geoinformation and Cartography; Springer: Cham, Switzerland, 2020; pp. 327-348. [CrossRef]

22. Ramirez-Gomez, S.O.I.; Verweij, P.; Best, L.; van Kanten, R.; Rambaldi, G.; Zagt, R. Participatory 3D modelling as a socially engaging and user-useful approach in ecosystem service assessments among marginalized communities. Appl. Geogr. 2017, 83, 63-77. [CrossRef]

23. Siau, K.; Nah, F.F.H.; Mennecke, B.E.; Schiller, S.Z. Co-creation and collaboration in a virtual world: A 3d visualization design project in second life. J. Database Manag. 2010, 21, 1-13. [CrossRef]

24. Jenkins, H. Transmedia Storytelling and Entertainment: An annotated syllabus. Continuum 2010, 24, 943-958. [CrossRef]

25. Milgram, P.; Kishimo, F. A taxonomy of mixed reality. IEICE Trans. Inf. Syst. 1994, 77, 1321-1329.

26. Morrelo, G. The City as a Time Machine: Urban Time Policies in Italy. Plan. Theor. Prac. 1999, 8.

27. Britisch Museum. Available online: https:/ / britishmuseum.withgoogle.com/ (accessed on 27 March 2021).

28. Mijic, N. Advanced Technologies, Systems, and Applications; Hadžikadić, M., Avdaković, S., Eds.; Lecture Notes in Networks and Systems; Springer International Publishing: Cham, Switzerland, 2017; Volume 3, ISBN 978-3-319-47294-2.

29. Chenaux, A.; Murphy, M.; Pavia, S.; Fai, S.; Molnar, T.; Cahill, J.; Lenihan, S.; Corns, A. A review of 3D GIS for use in creating virtual historic Dublin. ISPRS Ann. Photogramm. Remote Sens. Spat. Inf. Sci. 2019, 42, 249-254. [CrossRef]

30. Cecchini, C. From data to 3D digital archive: A GIS-BIM spatial database for the historical centre of Pavia (Italy). J. Inf. Technol. Constr. 2019, 24, 459-471. [CrossRef]

31. Jedlička Ing, K. A Comprehensive Overview of A Core of 3D GIS. In Proceedings of the 7th International Conference on Cartography and GIS, Sozopol, Bulgaria, 18-23 June 2018; pp. 464-472.

32. Van de Weghe, N.; de Roo, B.; Qiang, Y.; Versichele, M.; Neutens, T.; de Maeyer, P. The continuous spatio-temporal model (CSTM) as an exhaustive framework for multi-scale spatio-temporal analysis. Int. J. Geogr. Inf. Sci. 2014, 28, 1047-1060. [CrossRef] 
33. Qiang, Y.; Van de Weghe, N. Re-arranging space, time and scales in GIS: Alternative models for multi-scale spatio-temporal modeling and analyses. ISPRS Int. J. Geo-Inf. 2019, 8, 72. [CrossRef]

34. Arroyo Ohori, K.; Ledoux, H.; Stoter, J. Storing a 3D city model, its levels of detail and the correspondences between objects as a 4D combinatorial map. ISPRS Ann. Photogramm. Remote Sens. Spat. Inf. Sci. 2015, 2, 1-8. [CrossRef]

35. Ohori, K.A.; Ledoux, H.; Stoter, J. Visualising higher-dimensional spacetime and space-scale objects as projections to R3. PeerJ Comput. Sci. 2017, 2017. [CrossRef]

36. Périnaud, C. Changement urbain et imaginaires aménageurs: Une approche par l'exploration spatio-temporelle des sources d'histoire urbaine dans un SIG 4D. Développement Durable Territ. 2018, 9. [CrossRef]

37. Münster, S.; Friedrichs, K.; Kröber, C.; Bruschke, J.; Henze, F.; Maiwald, F.; Niebling, F. Urban history in 4 dimensions-Supporting research and education. Int. Arch. Photogramm. Remote Sens. Spat. Inf. Sci. ISPRS Arch. 2017, 42, 525-530. [CrossRef]

38. Bitelli, G.; Dellapasqua, M.; Girelli, V.A.; Sbaraglia, S.; Tini, M.A. Historical photogrammetry \& terrestrial laser scanning for the 3D virtual reconstruction of destroyed structures: A case study in Italy. Int. Arch. Photogramm. Remote Sens. Spat. Inf. Sci. ISPRS Arch. 2017, 42, 113-119. [CrossRef]

39. Miranda, R.; Valle Melón, J.M. Recovering old stereoscopic negatives and producing digital 3D models of former appearances of historic buildings. Int. Arch. Photogramm. Remote Sens. Spat. Inf. Sci. ISPRS Arch. 2017, 42, 601-608. [CrossRef]

40. Lonneville, B.; Vanhaeren, N.; Vandenbulcke, A.; De Wulf, A.; De Maeyer, P. Building a Virtual Time Machine for the Ancient Ruins of Jiaohe. In Proceedings of the 8th International congress on Archaeology, Computer Graphics, Cultural Heritage and Innovation (ARQUEOLÓGICA 2.0), Valencia, Spain, 5-7 September 2016; pp. 400-403.

41. Niebling, F.; Maiwald, F.; Barthel, K.; Latoschik, M.E. 4D augmented city models, photogrammetric creation and dissemination. Commun. Comput. Inf. Sci. 2018, 817, 196-212. [CrossRef]

42. Brůha, L.; Laštovička, J.; Palatý, T.; Štefanová, E.; Štych, P. Reconstruction of Lost Cultural Heritage Sites and Landscapes: Context of Ancient Objects in Time and Space. ISPRS Int. J. Geo-Inf. 2020, 9, 604. [CrossRef]

43. Stathopoulou, E.K.; Georgopoulos, A.; Panagiotopoulos, G.; Kaliampakos, D. Crowdsourcing lost cultural heritage. ISPRS Ann. Photogramm. Remote Sens. Spat. Inf. Sci. 2015, 2, 295-300. [CrossRef]

44. Wolberg, G.; Zokai, S. PhotoSketch: A photocentric urban 3D modeling system. Vis. Comput. 2018, 34, 605-616. [CrossRef]

45. Guidi, G.; Frischer, B.; De Simone, M.; Cioci, A.; Spinetti, A.; Carosso, L.; Micoli, L.L.; Russo, M.; Grasso, T. Virtualizing ancient Rome: 3D acquisition and modeling of a large plaster-of-Paris model of imperial Rome. Videometrics VIII 2005, 5665, 119. [CrossRef]

46. Noardo, F. Architectural heritage semantic 3D documentation in multi-scale standard maps. J. Cult. Herit. 2018, 32, 156-165. [CrossRef]

47. Pepe, M.; Costantino, D.; Alfio, V.S.; Angelini, M.G.; Garofalo, A.R. A CityGML multiscale approach for the conservation and management of cultural heritage: The case study of the old town of Taranto (Italy). ISPRS Int. J. Geo-Inf. 2020, 9, 449. [CrossRef]

48. Coli, M.; Ciuffreda, A.L.; Micheloni, M. An informative content 3d model for the hall holding the resurrection of christ by piero della francesca mural painting at sansepolcro, Italy. ISPRS Ann. Photogramm. Remote Sens. Spat. Inf. Sci. 2019, 42, 435-442. [CrossRef]

49. Nishida, G.; Bousseau, A.; Aliaga, D.G.; Nishida, G.; Bousseau, A.; Aliaga, D.G.; Modeling, P. Procedural Modeling of a Building from a Single Image. Comput. Graph. Forum 2018, 37, 415-429. [CrossRef]

50. Hu, Z.; Qin, X. Extended interactive and procedural modeling method for ancient Chinese architecture. Multimed. Tools Appl. 2020, 80, 5773-5807. [CrossRef]

51. Haegler, S.; Müller, P.; Van Gool, L. Procedural Modeling for Digital Cultural Heritage. EURASIP J. Image Video Process. 2009, 2009, 1-11. [CrossRef]

52. Grilli, E.; Remondino, F. Machine learning generalisation across different 3D architectural heritage. ISPRS Int. J. Geo-Inf. 2020, 9, 379. [CrossRef]

53. Kim, S.; Kim, D.; Choi, S. CityCraft: 3D virtual city creation from a single image. Vis. Comput. 2020, 36, 911-924. [CrossRef]

54. Romereborn. Available online: https://romereborn.org/content/roman-forum (accessed on 25 February 2021).

55. Kersten, T.P.; Keller, F.; Saenger, J.; Schiewe, J. Automated generation of an historic 4D city model of hamburg and its visualisation with the GE engine. In Progress in Cultural Heritage Preservation; Lecture Notes in Computer Science; Springer: Berlin/Heidelberg, Germany, 2012; Volume 7616, pp. 55-65. [CrossRef]

56. Kaplan, F.; Di Lenardo, I. The advent of the 4D mirror world. Urban Plan. 2020, 5, 307-310. [CrossRef]

57. Metze, T. Visualization in environmental policy and planning: A systematic review and research agenda. J. Environ. Policy Plan. 2020, 22, 745-760. [CrossRef]

58. Pánek, J. Mapping citizens' emotions: Participatory planning support system in Olomouc, Czech Republic. J. Maps 2019, 15, 8-12. [CrossRef]

59. Onyimbi, J.R.; Koeva, M.; Flacke, J. Public participation using 3D web-based city models: Opportunities for e-participation in Kisumu, Kenya. ISPRS Int. J. Geo-Inf. 2018, 7, 454. [CrossRef]

60. Brovelli, M.A.; Minghini, M.; Zamboni, G. Participatory GIS: Experimentations for a 3D social virtual globe. Int. Arch. Photogramm. Remote Sens. Spat. Inf. Sci. ISPRS Arch. 2013, XL-2/W2, 13-18. [CrossRef]

61. Hu, Y.; Lv, Z.; Wu, J.; Janowicz, K.; Zhao, X.; Yu, B. A multistage collaborative 3D GIS to support public participation. Int. J. Digit. Earth 2015, 8, 212-234. [CrossRef] 
62. Counsell, J.; Smith, S.; Bates-Brkljac, N. Web 3D based dialogue for public participation and the VEPs Project. In Proceedings of the Tenth International Conference on Information Visualisation (IV'06), London, UK, 5-7 July 2006; pp. 343-348. [CrossRef]

63. Chassin, T.; Ingensand, J.; Lotfian, M.; Ertz, O.; Joerin, F. Challenges in creating a 3D participatory platform for urban development. Adv. Cartogr. GIScience ICA 2019, 1, 1-8. [CrossRef]

64. Constantinescu, T.I.; Devisch, O.; Huybrechts, L. Participation, for whom? The potential of gamified participatory artefacts in uncovering power relations within urban renewal projects. ISPRS Int. J. Geo-Inf. 2020, 9, 319. [CrossRef]

65. Fukuda, T.; Kaga, A.; Izumi, H.; Terashima, T. Citizen Participatory Design Method Using VR and a Blog as a Media in the Process. Int. J. Archit. Comput. 2009, 7, 217-233. [CrossRef]

66. Wu, H.; He, Z.; Gong, J. A virtual globe-based 3D visualization and interactive framework for public participation in urban planning processes. Comput. Environ. Urban Syst. 2010, 34, 291-298. [CrossRef]

67. Destination Earth, Shaping Europe's Digital Future. Available online: https://digital-strategy.ec.europa.eu/en/policies/ destination-earth (accessed on 10 June 2021).

68. Schrotter, G.; Hürzeler, C. The Digital Twin of the City of Zurich for Urban Planning. PFG J. Photogramm. Remote Sens. Geoinf. Sci. 2020, 88, 99-112. [CrossRef]

69. Bonacini, E. Stories on Geographies: Geo-Social Tagging for Co-Creation of Cultural Value. Int. J. Herit. Digit. Era 2013, 2, 221-243. [CrossRef]

70. Panori, A.; Kakderi, C.; Komninos, N.; Fellnhofer, K.; Reid, A.; Mora, L. Smart systems of innovation for smart places: Challenges in deploying digital platforms for co-creation and data-intelligence. Land Use Policy 2020, 104631. [CrossRef]

71. Ramaswamy, V.; Ozcan, K. What is co-creation? An interactional creation framework and its implications for value creation. J. Bus. Res. 2018, 84, 196-205. [CrossRef]

72. Fukuda, T.; Takeuchi, H. Development of use flow of 3D CAD / VR software for citizens who are non-specialists in city design. In Proceedings of the 15th International Conference on Computer Aided Architectural Design Research in Asia, Hong Kong, China, 7-10 April 2010; pp. 521-530.

73. Mueller, J.; Lu, H.; Chirkin, A.; Klein, B.; Schmitt, G. Citizen Design Science: A strategy for crowd-creative urban design. Cities 2018, 72, 181-188. [CrossRef]

74. Means, B.K. Promoting a More Interactive Public Archaeology. Adv. Archaeol. Pract. 2015, 3, 235-248. [CrossRef]

75. Jung, T.H.; tom Dieck, M.C. Augmented reality, virtual reality and 3D printing for the co-creation of value for the visitor experience at cultural heritage places. J. Place Manag. Dev. 2017, 10, 140-151. [CrossRef]

76. Bollwerk, E.; Connolly, R.; McDavid, C. Co-Creation and Public Archaeology. Adv. Archaeol. Pract. 2015, 3, 178-187. [CrossRef]

77. Barbuti, N.; De Felice, G.; Di Zanni, A.; Russo, P.; Valentini, A. Creating Digital Culture by digitizing Cultural Heritage: The Crowddreaming living lab method. Um. Digit. 2020, 9, 19-34. [CrossRef]

78. Adamu, Z.A.; Emmitt, S.; Soetanto, R. Social BIM: Co-creation with shared situational awareness. J. Inf. Technol. Constr. 2015, 20, 230-252.

79. Landers, R.N.; Auer, E.M.; Collmus, A.B.; Armstrong, M.B. Gamification Science, Its History and Future: Definitions and a Research Agenda. Simul. Gaming 2018, 49, 315-337. [CrossRef]

80. Olszewski, R.; Cegiełka, M.; Szczepankowska, U.; Wesołowski, J. Developing a serious game that supports the resolution of social and ecological problems in the toolset environment of cities: Skylines. ISPRS Int. J. Geo-Inf. 2020, 9, 118. [CrossRef]

81. Bassanino, M.; Fernando, T.; Campion, S.; Alkandari, A.; Masior, J.; Iao, F. Design 3D On-Line Gaming Environment for Learning how to Design Green Buildings. Bus. Manag. Rev. 2015, 6, 137-150.

82. Prandi, C.; Melis, A.; Prandini, M.; Delnevo, G.; Monti, L.; Mirri, S.; Salomoni, P. Gamifying cultural experiences across the urban environment. Multimed. Tools Appl. 2019, 78, 3341-3364. [CrossRef]

83. Morschheuser, B.; Hamari, J.; Koivisto, J. Gamification in crowdsourcing: A review. In Proceedings of the Hawaii International Conference on System Sciences, Koloa, HI, USA, 5-8 July 2016; pp. 4375-4384. [CrossRef]

84. Martella, R.; Kray, C.; Clementini, E. A gamification framework for volunteered geographic information. Lect. Notes Geoinf. Cartogr. 2015, 217, 73-89. [CrossRef]

85. Da Silva, C.C.; Da Silva Filho, A.G.; Monteiro, J.S.; Dos Santos, W.P. Developing 3D human-computer interfaces and serious games for health education in the brazilian countryside using participatory design and popular education. In Proceedings of the IEEE International Conference on Systems, Man and Cybernetics, San Diego, CA, USA, 5-8 October 2014; pp. $2971-2976$. [CrossRef]

86. Mat, R.C.; Shariff, A.R.M.; Zulkifli, A.N.; Rahim, M.S.M.; Mahayudin, M.H. Using game engine for 3D terrain visualisation of GIS data: A review. IOP Conf. Ser. Earth Environ. Sci. 2014, 20. [CrossRef]

87. Carbonell-Carrera, C.; Gunalp, P.; Saorin, J.L.; Hess-Medler, S. Think spatially with game engine. ISPRS Int. J. Geo-Inf. 2020, 9 , 159. [CrossRef]

88. Buyuksalih, I.; Bayburt, S.; Buyuksalih, G.; Baskaraca, A.P.; Karim, H.; Rahman, A.A. 3D modelling and visualization based on the unity game engine-Advantages and challenges. ISPRS Ann. Photogramm. Remote Sens. Spat. Inf. Sci. 2017, 4, 161-166. [CrossRef]

89. Laksono, D.; Aditya, T. Utilizing a game engine for interactive 3D topographic data visualization. ISPRS Int. J. Geo-Inf. 2019, 8, 361. [CrossRef]

90. Mapbox for Unity. Available online: https://www.mapbox.com/unity (accessed on 5 March 2021).

91. Blender. Available online: https://www.blender.org (accessed on 14 April 2021). 
92. Open-source Game Engine from Blender. Available online: https:/ / upbge.org (accessed on 10 June 2021).

93. Autodesk-for-Games. Available online: https://www.autodesk.com/campaigns/autodesk-for-games (accessed on 10 June 2021).

94. De Leeuw, D.; De Maeyer, P.; De Cock, L. A Gamification-Based Approach on Indoor Wayfinding Research. ISPRS Int. J. Geo-Inf. 2020, 9, 423. [CrossRef]

95. Alatalo, T.; Pouke, M.; Koskela, T.; Hurskainen, T.; Florea, C.; Ojala, T. Two real-world case studies on 3dweb applications for participatory urban planning. In Proceedings of the 22nd International Conference on 3D Web Technology (Web3D 2017), Brisbane, Australia, 5-7 June 2017. [CrossRef]

96. Cláudio, A.P.; Carmo, M.B.; de Carvalho, A.A.; Xavier, W.; Antunes, R.F. Recreating a medieval urban scene with virtual intelligent characters: Steps to create the complete scenario. Virtual Archaeol. Rev. 2017, 8, 31-41. [CrossRef]

97. Gheorghiu, D.; Stefan, L. Augmented Virtuality as an Instrument for a Better Learning of History. In Proceedings of the 13th International Conference on Virtual Learning (ICVL 2018), Alba Iulia, Romania, 26-27 October 2018; Volume 2, pp. $299-305$.

98. Kaplan, K.; Grant, J.; Güçlü, K.; Ünal, Ç.; Yakupoğlu, E. An Example for 3D Animated Character Design Process: The Lost City Antioch. Procedia Soc. Behav. Sci. 2014, 122, 65-71. [CrossRef]

99. Keil, J.; Edler, D.; Schmitt, T.; Dickmann, F. Creating Immersive Virtual Environments Based on Open Geospatial Data and Game Engines. KN J. Cartogr. Geogr. Inf. 2021, 71, 53-65. [CrossRef]

100. Schmohl, S.; Tutzauer, P.; Haala, N. Stuttgart City Walk: A Case Study on Visualizing Textured DSM Meshes for the General Public Using Virtual Reality. PFG J. Photogramm. Remote Sens. Geoinf. Sci. 2020, 88, 147-154. [CrossRef]

101. Zhang, L.; Chen, S.; Dong, H.; El Saddik, A. Visualizing Toronto City Data with HoloLens: Using Augmented Reality for a City Model. IEEE Consum. Electron. Mag. 2018, 7, 73-80. [CrossRef]

102. Mertens, L.; Van Cauwenberg, J.; Deforche, B.; Van de Weghe, N.; Matthys, M.; Van Dyck, D. Using virtual reality to investigate physical environmental factors related to cycling in older adults: A comparison between two methodologies. J. Transp. Heal. 2020, 19, 100921. [CrossRef]

103. Julin, A.; Jaalama, K.; Virtanen, J.P.; Maksimainen, M.; Kurkela, M.; Hyyppä, J.; Hyyppä, H. Automated multi-sensor 3D reconstruction for the web. ISPRS Int. J. Geo-Inf. 2019, 8, 221. [CrossRef]

104. Guarnieri, A.; Pirotti, F.; Vettore, A. Cultural heritage interactive 3D models on the web: An approach using open source and free software. J. Cult. Herit. 2010, 11, 350-353. [CrossRef]

105. Groenendyk, M. Cataloging the 3D web: The availability of educational 3D models on the internet. Libr. Hi Tech 2016, 34, 239-258. [CrossRef]

106. Chittaro, L.; Ranon, R. Web3D technologies in learning, education and training: Motivations, issues, opportunities. Comput. Educ. 2007, 49, 3-18. [CrossRef]

107. Valente, R.; Brumana, R.; Oreni, D.; Banfi, F.; Barazzetti, L.; Previtali, M. Object-oriented approach for 3D archaeological documentation. Int. Arch. Photogramm. Remote Sens. Spat. Inf. Sci. ISPRS Arch. 2017, 42, 707-712. [CrossRef]

108. Krämer, M.; Gutbell, R. A case study on 3D geospatial applications in the Web using state-of-the-art WebGL frameworks. In Proceedings of the 20th International Conference on 3D Web Technology, Heraklion, Greece, 18-21 June 2015; pp. 189-197. [CrossRef]

109. Buyukdemircioglu, M.; Kocaman, S. Reconstruction and efficient visualization of heterogeneous 3D city models. Remote Sens. 2020, 12, 2128. [CrossRef]

110. Murshed, S.M.; Al-Hyari, A.M.; Wendel, J.; Ansart, L. Design and implementation of a 4D web application for analytical visualization of smart city applications. ISPRS Int. J. Geo-Inf. 2018, 7, 276. [CrossRef]

111. Kilsedar, C.E.; Brovelli, M.A. Multidimensional Visualization and Processing of Big Open Urban Geospatial Data on theWeb. ISPRS Int. J. Geo-Inf. 2020, 9, 434. [CrossRef]

112. Maiwald, F.; Bruschke, J.; Lehmann, C.; Niebling, F. A 4D information system for the exploration of multitemporal images and maps using photogrammetry, web technologies and Vr/Ar. Virtual Archaeol. Rev. 2019, 10, 1-13. [CrossRef]

113. Koeva, M.N. 3D modelling and interactive web-based visualization of cultural heritage objects. Int. Arch. Photogramm. Remote Sens. Spat. Inf. Sci. ISPRS Arch. 2016, 41, 297-303. [CrossRef]

114. Boutsi, A.M.; Ioannidis, C.; Soile, S. An integrated approach to $3 \mathrm{D}$ web visualization of cultural heritage heterogeneous datasets. Remote Sens. 2019, 11, 2508. [CrossRef]

115. OGC 3D Tiles Format. Available online: https://www.ogc.org/standards/3DTiles (accessed on 29 March 2021).

116. Statham, N. Scientific rigour of online platforms for 3D visualisation of heritage. Virtual Archaeol. Rev. 2019, 10, 1-16. [CrossRef]

117. Evangelidis, K.; Papadopoulos, T.; Papatheodorou, K.; Mastorokostas, P.; Hilas, C. 3D geospatial visualizations: Animation and motion effects on spatial objects. Comput. Geosci. 2018, 111, 200-212. [CrossRef]

118. Scolari, C.A. Transmedia Storytelling: Implicit Consumers, Narrative Worlds, and Branding in Contemporary Media Production. Int. J. Commun. 2009, 3, 586-606.

119. Dudacek, O. Transmedia Storytelling in Education. Procedia Soc. Behav. Sci. 2015, 197, 694-696. [CrossRef]

120. Zhang, L.; Bowman, D.A.; Jones, C.N. Exploring effects of interactivity on learning with interactive storytelling in immersive virtual reality. In Proceedings of the 2019 11th International Conference on Virtual Worlds and Games for Serious Applications (VS-Games), Vienna, Austria, 4-6 September 2019. [CrossRef]

121. Brusk, J.; Engström, H. Marvinter: A case study of an inclusive transmedia storytelling production. Convergence 2020, $27,103-123$. [CrossRef] 
122. Carol, E. The Pleasure of 3D Storytelling with ArcGIS StoryMaps. Available online: https://www.esri.com/arcgis-blog/products / arcgis-storymaps/mapping/the-pleasures-of-3d-storytelling-with-arcgis-storymaps (accessed on 10 March 2021).

123. My House, My Dream (Mijn Huis, Mijn Droom). Available online: www.youtube.com/watch? $=$ =SynsCb_rMiM (accessed on 11 May 2021).

124. de Andrade, B.; Poplin, A.; de Sena, Í.S. Minecraft as a tool for engaging children in urban planning: A Case study in Tirol Town, Brazil. ISPRS Int. J. Geo-Inf. 2020, 9, 170. [CrossRef]

125. 3D City Game Ghent. Available online: https://stad.gent/nl/over-gent-en-het-stadsbestuur/stadsbestuur/wat-doet-hetbestuur/gent-digitale-stad/gent-3d-virtuele-realiteit-vrarmr/droom-mee-3d/3d-citygame-ghent (accessed on 29 April 2021).

126. Meetup: 3D City Game Ghent. Available online: https://stad.gent/nl/over-gent-en-het-stadsbestuur/stadsbestuur/watdoet-het-bestuur/gent-digitale-stad/gent-3d-virtuele-realiteit-vrarmr/droom-mee-3d/3d-citygame-ghent (accessed on 28 April 2021).

127. Sketchup: Matching-Photo-Model-or-Model-Photo. Available online: https://help.sketchup.com/en/sketchup/matching-photomodel-or-model-photo (accessed on 18 February 2021).

128. Biancardo, S.A.; Russo, F.; Veropalumbo, R.; Vorobjovas, V.; Dell'acqua, G. Modeling roman pavements using heritage-bim: A case study in pompeii. Balt. J. Road Bridg. Eng. 2020, 15, 34-46. [CrossRef]

129. Sketchup. Available online: https:/ / www.sketchup.com/ (accessed on 25 February 2021).

130. Github. Available online: https:/ / github.com/ (accessed on 25 February 2021).

131. Slack. Available online: https:/ / slack.com (accessed on 2 March 2021).

132. Trello. Available online: https: / / trello.com (accessed on 25 February 2021).

133. Plastic SCM. Available online: https:/ / www.plasticscm.com/ (accessed on 29 April 2021).

134. Unity. Available online: https://unity.com/ (accessed on 28 April 2021).

135. Unity Asset Store. Available online: https:/ /assetstore.unity.com/ (accessed on 28 April 2021).

136. Skylinesoft (Terraexplorer). Available online: https:/ /www.skylinesoft.com/terraexplorer-desktop (accessed on 19 April 2021 ).

137. Google Earth. Available online: https://www.google.com/intl/eng/earth/ (accessed on 19 April 2021).

138. Álvarez, M.; Raposo, J.F.; Miranda, M.; Bello, A.; Barbero, M. Web 3D: A CityGML viewer for cross-domain problem resolution. Appl. Geomat. 2020, 13, 71-87. [CrossRef]

139. Guimaraes, F.; Figueiredo, M.; Rodrigues, J. Augmented Reality and Storytelling in heritage application in public gardens: Caloust Gulbenkian Foundation Garden. In Proceedings of the 2015 Digital Heritage, Granada, Spain, 28 September-2 October 2015; pp. 317-320.

140. Van Wittenberghe, D.B.; D'hondt, B. A historical walk in 3D (Een historische wandeling in 3D). In Het Spaans Kasteel Gent, van Dwangburcht tot Woonwijk; Fabien Audooren \& Christine De Zutter: Gent, Belgium, 2018; pp. 226-239. ISBN 978-90-814-1463-o.

141. Sánchez-Castillo, S.; Mora-Llabata, M.R. Transmedia Storytelling As Collaborative Environment and Autonomous in Higher Education. In Proceedings of the EDULEARN19 Conference, Palma, Spain, 1-3 July 2019; Volume 1, pp. 8436-8441. [CrossRef]

142. Hovious, A.; Shinas, V.H.; Harper, I. The Compelling Nature of Transmedia Storytelling: Empowering Twenty First-Century Readers and Writers Through Multimodality. Technol. Knowl. Learn. 2020. [CrossRef]

143. Charles, V. Holy Roman Emperor. Available online: https://en.wikipedia.org/wiki/Charles_V,_Holy_Roman_Emperor (accessed on 8 February 2021).

144. Prinsenhof. Available online: https:/ / commons.wikimedia.org/w/index.php?curid=46308746 (accessed on 8 February 2021).

145. Visit Gent. Available online: https://visit.gent.be/en/see-do/prinsenhof (accessed on 8 February 2021).

146. Gentse Passages. Available online: https://gentsepassages.webnode.be (accessed on 8 February 2021).

147. Gent Geprent-Maquettes Prinses' Court Castle. Available online: https://www.gent-geprent.com/standbeelden-2/ standbeelden-deel-3/maquette-prinsenhof (accessed on 8 February 2021).

148. The World of Kina, Museum. Available online: https:/ / dewereldvankina.stad.gent/ (accessed on 13 April 2021).

149. Maquette Prinsenhof. Available online: https://cultuur.stad.gent/nl/street-art/maquette-prinsenhof (accessed on 8 February 2021).

150. Montusiewicz, J.; Barszcz, M.; Dziedzic, K.; Kęsik, J.; Miłosz, M.; Tokovarov, M. the Concept of a 3D Board Game To Recognise Architectural Monuments. In Proceedings of the INTED2017, Valencia, Spain, 6-8 March 2017; Volume 1, pp. 8665-8674. [CrossRef]

151. Shaping24. Available online: https://www.europeanheritageawards.eu/winners/shaping-24-promoting-heritage-norwichghent (accessed on 5 April 2021).

152. Film "Back to the Future". Available online: https://en.wikipedia.org/wiki/Back_to_the_Future (accessed on 10 February 2021).

153. Sustainable Development Goals Ghent Online. Available online: https://stad.gent/en/international-policy/think-global-actlocal/sustainable-development-goals (accessed on 4 February 2021).

154. Stapleton, C.; Hughes, C.; Moshell, M.; Micikevicius, P.; Altman, M. Applying mixed reality to entertainment. Computer 2002, 35, 122-124. [CrossRef]

155. Ohori, K.A.; Ledoux, H.; Stoter, J. Modeling and manipulating spacetime objects in a true 4D model. J. Spat. Inf. Sci. 2017, 14, 61-93. [CrossRef]

156. Neutens, T.; Witlox, F.; Demaeyer, P. Individual accessibility and travel literature review on time geography possibilities. Eur. J. Trans. Infrastruct. Res. 2007, 7. [CrossRef]

157. Kwan, M. Space Time Path. Available online: http:/ / meipokwan.org/Gallery/STPaths (accessed on 24 February 2021). 
158. Pine, J., II. Infinite Possibility, Multiverse. Available online: https://www.slideshare.net/momoams/jospeh-pine-ii/25-Infinite_ Possibility_Mobile_Mondays_June (accessed on 24 February 2021).

159. Bembibre, C.; Strlič, M. Smell of heritage: A framework for the identification, analysis and archival of historic odours. Herit. Sci. 2017, 5, 1-11. [CrossRef]

160. Odeuropa. Available online: https:/ / odeuropa.eu/ (accessed on 24 February 2021). 